
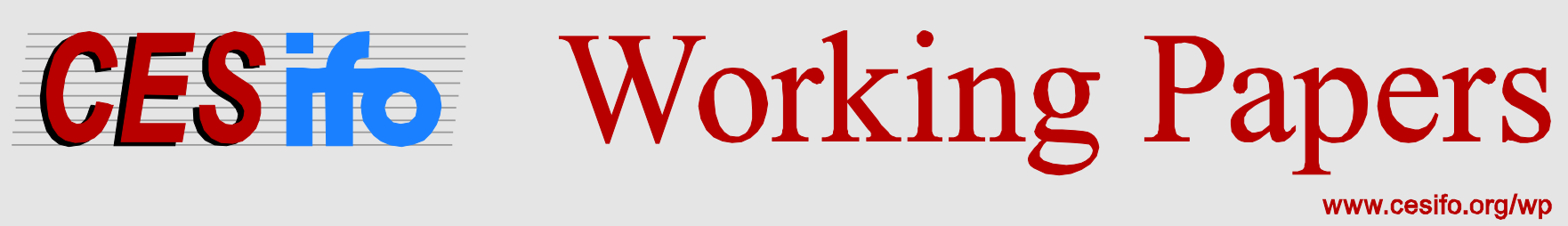

\title{
Individual Investments in Education and Health: Policy Responses and Interactions
}

\author{
Jared C. Carbone \\ Snorre Kverndokk
}

CESIFO WORKING PAPER NO. 6154

CATEGORY 5: ECONOMICS OF EDUCATION

OCTOBER 2016

An electronic version of the paper may be downloaded

- from the SSRN website:

- from the RePEc website:

- from the CESifo website:

WWW.SSRN.com

Www.RePEc.org

www.CESifo-group.org/wp 


\title{
Individual Investments in Education and Health: Policy Responses and Interactions
}

\begin{abstract}
Empirical studies show that years of schooling are positively correlated with good health. The implication may go from education to health, from health to education, or from factors that influence both variables. We formalize a model that determines an individual's demand for knowledge and health based on the causal effects, and study the impacts on the individual's decisions of policy instruments such as subsidies on medical care, subsidizing schooling, income tax reduction, lump sum transfers and improving health at young age. Our results indicate that income redistribution policies may be the best instrument to improve welfare, while a medical care subsidy is the best instrument for longevity. Subsidies to medical care or education would require large imperfections in these markets to be more welfare improving than distributional policies.
\end{abstract}

JEL-Codes: C610, D910, I120, I210.

Keywords: demand for health, demand for education, human capital, numerical modeling, causality.

Jared C. Carbone

Division of Economics and Business

Colorado School of Mines

Engineering Hall

$81615^{\text {th }}$ Street Golden

USA - Colorado 80401

jcarbone@mines.edu
Snorre Kverndokk

Ragnar Frisch Centre

for Economic Research

Gaustadalléen 21

Norway - 0349 Oslo

snorre.kverndokk@frisch.uio.no

October 2016

This paper is part of the HERO program at the University of Oslo, and is funded by the Norwegian Research Council. We are indebted to discussions with Sverre Kittelsen and to comments from Michael Grossman, Gustav Kjellsson, Ramona Molitor and the participants at the Symposium on Human Capital and Health Behavior in Gothenburg, 19-20 May 2016. 


\section{Introduction}

Empirical studies show that years of schooling are positively correlated with good health (see, e.g., Huisman et al., 2005, for European countries, and Cutler et al., 2011, for the US). Educated people engage more in exercise, report fewer sick leaves and have longer expected lifetimes. Education is more strongly correlated with health than with occupation and income. ${ }^{1}$

A large and active empirical literature seeks to explain this pattern, focusing on three, broad possibilities (Grossman, 2000; Cutler and Lleras-Muney, 2007). First, higher education may cause better health; having more education could make individuals more efficient in maintaining their health, taking better advantage of information about their health status and strategies available for affecting it. Higher education also leads to better job opportunities - with higher levels of compensation, which can be devoted to health care and lower exposure to job-related health risks - and higher social status. These factors may also give highly educated individuals an incentive to invest in health to increase the probability of enjoying a brighter future.

Second, better health may cause individuals to attain higher levels of education. Healthier students may be more willing to invest time in education or they may be more efficient in producing knowledge. As an illustration of the first point, Grossman (2003) suggests that better health causes more schooling because a lower mortality increases the number of years over which the returns from investments in knowledge can be collected. The latter point suggests that better health increases the ability to learn, given equal effort. Better health also makes working while a student more likely, reducing the monetary costs of studying.

Finally, there may be other factors that influence both health and education in the same direction. Individuals may possess certain characteristics - time preferences, initial resources, traumatic experiences or socio-economic background for example - which make it more or less likely that they obtain higher levels of both health and education (Fuchs, 1982). For instance, putting less weight on future outcomes (high time preference rate) would imply that one should investment less in activities for which the costs come today and the benefits arrive in the future. Both health and education investments fall into this category. An individual's socio-economic background

\footnotetext{
${ }^{1}$ See our discussion of the evidence in Section 2 of this paper.
} 
may define the expectations of her peers when it comes to health behavior and educational attainment. Finally, individuals with higher innate cognitive abilities may be more efficient at producing higher levels of health and education.

Both health and education are top public policy concerns. If equal access to health or education is a political goal, policy interventions that target health, education or general well-being may fulfill it to varying degrees and with varying costs. If the causal effect of education on health is strong, there may be reasons to promote education beyond fulfilling society's educational goals. Similarly, if the causal effect of health on education is strong, a policy improving health at young age may be justified. In addition, if background and socio-economic characteristics are important for both health and education, it may be an argument for general distributional policy. ${ }^{2}$

In this paper we focus on these policy concerns and study how different policy measures to improve health and education can affect the decisions of the individuals when making their choices on how much to invest in these activities. This may be important as a guide for policy decisions. To do this, we model an individual who chooses how much to invest in education and health, as well as how much to work, consume and save throughout adult life. This allows us to generate predictions on how individuals may react to different policies based on the different causal effects. We first develop a simple, analytical model to generate intuition. We find that many of the policy instruments have indeterminate effects, which we can decompose into determinate partial effects. Then we develop a richer, calibrated numerical model, allowing us to narrow the range of predictions produced by the analytical model and explore the quantitative significance of our main findings.

To operationalize the idea that different policies target different outcomes, we study the effects of subsidies on medical care (health policy), subsidies on schooling (education policy), an incometax reduction (distributional policy) and two different counterfactuals that focus on early-life interventions - a lump-sum wealth transfer and an exogenous improvement in health.

\footnotetext{
${ }^{2}$ In a series of papers, James Heckman argues for early child intervention (see, e.g., Heckman, 2007) instead of adult investments for later health outcomes.
} 
The wealth-transfer policy also functions as a benchmark against which to judge the performance of the other policies we consider. From a normative view, a simple neoclassical model of consumer choice (such as the one we construct) will predict that a lump-sum wealth transfer welfare-dominates policies targeted specifically at education or health from the individual perspective. The individual is only concerned about the impacts of the investments on own welfare. Nevertheless, a number of important market failures are relevant in this policy domain. Education is often considered an important public good, a major motivation for the establishment of public schools; private decisions to investment in education fail to take into account its full social benefits. Restrictions on behavior such as social expectations, addiction, bounded rationality and uncertainty may also lead individuals to make suboptimal choices and, as a result, justify corrective policy measures. Market failures and restrictions are not explicitly studied in this paper, but we may evaluate how important these failures would need to be in order justify them from an efficiency perspective.

In the analytical model, we find that the different policies in many cases give substitution and income effects in different directions, and the effects on health and education investments are therefore often indeterminate without calibrated and specific functional forms. Nevertheless, the model shed lights on the mechanisms present that are useful for the numerical model. Some examples are that a price subsidy on medical care increases the purchase of medical care, but has an uncertain effect on education; a subsidy on schooling affects monetary investments in schooling positively, but not necessarily the time spent on schooling; and that an income tax reduction has a positive effect on both monetary investments in schooling and medical care.

The numerical model confirms these analytical results and, in addition, guides us where they are indeterminate and when we compare the impacts of the policy measures. Our numerical results indicate that income redistribution policies may be the best instrument to improve welfare, while a medical care subsidy is the best instrument for longevity. Subsidies to medical care or education would require large imperfections for health and education to be more welfare improving than distributional policies. They also suggest that underlying factors that affect both health and education may be the main explanation for the correlation shown empirically. 
There are several empirical studies on the relationship between health and education (see Section 2) but theoretical contributions are few. ${ }^{3}$ Becker (2007) is the first paper to outline how health investments and educational investments can be analyzed in a joint framework. He develops a simple two period model of joint decisions, as an example of how the human capital theory can be extended. Galama and van Kippersluis (2015) provide a more formal analytical model that describes an individual's joint investments in health capital and skill capital over time. However, neither of these studies analyzes the effects of different policies on the investment decisions.

Our numerical model builds on a tradition of studying individual health behavior and well-being using human capital theory. ${ }^{4}$ Recently, some numerical models have been developed to study investments in education and health. Strulik (2013) introduces a numerical model for analyzing the effect of cognitive ability on the social gradient in health, where the individual can invest in health based on consumption choices as well in education. In addition, Hai and Heckman (2015) develop and structurally estimate a dynamic lifecycle model of health, education and wealth to study impacts of credit constraints and rational addiction. Our paper differs from these studies by studying how policies aimed at increasing education or health affect interact with and affect other outcomes in this policy domain. We also demonstrate a new method of calibrating our numerical model by matching key moments in data on health and education investment decisions.

The paper is organized as follows. In Section 2, we survey the empirical evidence on the relationship between education and health. To illustrate the effects of different policy instrument, we analyze a two-period, analytical model in Section 3. Section 4 describes a more detailed

\footnotetext{
${ }^{3}$ The incentives for a consumer to invest in knowledge have been studied in human capital models (see, e.g., Becker, 1993; Ben-Porath 1967; Mincer, 1974). The pioneering model for the demand for health and health services (Grossman, 1972) also build on the human capital tradition, but considers education as an exogenous variable. Thus it cannot explore interactions between health and education investment decisions. Muurinen (1982) assumes that higher education reduces the depreciation of health capital (use-related depreciation) leading to allocative efficiency of education. Further, Becker and Mulligan (1997) endogenize the time preference rate by assuming that individuals can invest in goods or activities, such as schooling, to reduce this rate. In their model, health differences cause differences in time preferences because better health reduces mortality and raises future utility levels. See also the plea for development of comprehensive theoretical models in which the stock of health and knowledge are determined simultaneously in Grossman (2000, 2003).

${ }^{4}$ Some early studies were Gjerde et al. (2005), Carbone et al. (2005) and Murphy and Topel (2006). These papers have a Grossman-model structure, but do not include human capital accumulation. Carbone et al. (2005) does, however, include investments in both health capital and addiction capital. Numerical models also studying choices over the life-cycle include Scholz and Seshadri (2010), Halliday et al. (2010) and Koka et al. (2014). They study the interplay between consumption choices and investments in health and the motives underlying health investments, but again they do not include investments in education.
} 
numerical model, calibrated to match data for the US in Section 5. Section 6 describes the policy experiments while the simulation results are given in Section 7. The final section concludes.

\section{Empirical evidence on the causal effects ${ }^{5}$}

To test the causal effect from health to education, there have been several studies on birth weight, an indicator of initial health, and its implications for education and labor market outcomes. Almond et al. (2005) use American data and conclude that the short-term effects of low birth weight are rather small, while Behrman and Rosenzweig (2004) find significant long-term effects of low birth weight on education and wages. Using Norwegian data, Kristensen et al. (2004) and Black et al. (2007) confirm the results. There are also studies considering other measures of health. Sick children are more likely to miss school, to learn less while in school, to obtain fewer years of learning and to have a lower socio economic status as adults (Case et al., 2005; Madsen, 2012). Poor mental health in early childhood also has a large impact on years of schooling completed (Fletcher and Lehrer, 2009).

There is mixed evidence on the causal link from education to health. One way of studying this effect is to utilize the natural experiments of extensions to compulsory schooling. While some early studies found quite large effect of changes in compulsory schooling laws (Lleras-Muney, 2005; 2006), recent studies find no effect (e.g., Clark and Royer, 2010; Meghir et al., 2012; Jürges et al., 2012), with the exception of Fonesca and Zheng (2011) and van Kippersluis et al. (2011). Chou et al. (2010) use an extension of compulsory education in Taiwan to study mothers' and fathers' schooling on infant birth outcomes, and find favorable infant health outcomes. Currie and Moretti (2003) reach a similar conclusion in a study on U.S. data.

Other studies focus on outcomes for identical twins. The results from these are also a bit mixed. While some studies find no effects from education on health (e.g., Behrman et al., 2011; Amin et al., 2013; Madsen et al., 2010), Lundborg (2013) finds that completing high school improves selfreported health, chronic conditions and exercise behavior, but that additional schooling does not lead to additional health gains. Fujiwara and Kawachi (2009) find similar results. Studying

\footnotetext{
${ }^{5}$ For surveys, see Grossman and Kaestner (1997), Grossman (2000; 2008; 2015), Cutler and Lleras-Muney (2007), Cutler et al. (2011) and Mazumder (2012).
} 
military retirees, Edwards (2010) finds positive health returns to education, which monotonically diminish in age, suggesting that the effects of education on later-life health may be due to accumulation of knowledge and not through income and wealth achieved later in life. Buckles et al. (2016) also find positive health effects of college education, using the Vietnam War draft as an instrument variable.

Several studies have tried to estimate the causal effect of income - which depends on education and early-life health - on health. Adams et al. (2003), Contoyannis et al. (2004) and Smith (2007) all use panel data for identification and find no effect. Frijters et al. (2005) exploit the fact that East Germans received a large income transfer under German reunification, finding that it had a small, positive effect on health. Lindahl (2005) finds that winning the lottery causes a significant positive effect on health, while Apouey and Clark (2009) found positive effects on mental health, but negative effects on physical health due to an increase in risky behavior in the short run. A new study on lottery winners (Cesarini et al., 2016), find no convincing evidence on mortality, nor of the relationships between child developmental outcomes and household income. Finally, Grossman (1972) assumes that there are decreasing returns from income on health for higher levels of income. This is confirmed by several studies such as Chapman and Hariharan (1996).

Nevertheless, Cutler and Lleras-Muney (2007) show that after controlling for income and health insurance, education is still a significant determinant of health status in the US, and Cutler and Lleras-Muney (2010) find that the total returns from education may increase by 15 to 55 percent if they include their estimates of the health benefits from education. Thus, mechanisms other than the effect of education on income matter. The better educated tend to have less risky jobs, but Lahelma et al. (2004) and Cutler and Lleras-Muney (2007) find small effects of the labor environment. Education gives social status, which has documented effects on health (Marmot, 2004). Goldman and Smith (2002) find that more highly educated people are better able to manage disease. There is also evidence supporting the idea that more education leads to lower rates of smoking (de Walque, 2007; Fabrice and Jones, 2011). More generally, researchers find that the effect of education on health behaviors is significant (Brunello et al., 2012). On the other hand, Bijwaard and Van Kippersluis (2016) concludes that education explains very little of health 
variation after controlling for intelligence. Thus, to summarize, the question of whether more schooling does or does not cause better health, has not yet been resolved (Grossman, 2015).

The effect of factors that influence both health and education has also been tested. Fuchs (1982) and Leigh (1990) find that only a small portion of the education gradient is explained by differences in time preferences, which is supported by Cutler and Lleras-Muney (2010). On the other hand, Chiteji (2010) concludes that non-cognitive skills, such as the degree to which an individual is future-oriented, are associated with good health behavior. Also, van der Pol (2011) finds that the effects of education on health are reduced (but do not disappear) when controlling for individuals' time preferences, indicating a positive effect from such preferences. While Auld and Sidhu (2005) and Cutler and Lleras-Muney (2010) emphasize the importance of cognitive ability on the gradient, Conti and Heckman (2010) conclude differently, and find that early cognitive factors have a larger impact on educational attainment than on later life health, while early endowments in non-cognitive skills and health affect both.

To sum up, there appears to be some empirical evidence supporting all three causal mechanisms, but it is hard to find very significant effects.

\section{A two-period model}

To get the intuition on how the different policy measures may affect an individual's choices between consumption and investments in education and health, we set up a simple two-period model that captures the main features of the numerical model we present in the next section. The model shares similarities with the model suggested in Becker (2007), but differs in several aspects for instance that education has a direct impact both on utility and health, and that both health and education is dependent on time and money investments. The aim of the model is to explain the mechanisms that work in the more complicated numerical model.

In this model, a representative consumer maximizes the present value of utility over the two periods, where the first period is the present and the second period represents the future, i.e.,

$$
\mathrm{U}=\mathrm{u}\left(\mathrm{C}_{1}, \mathrm{E}_{1}, \mathrm{H}_{1}\right)+1 /(1+\rho) \cdot \mathrm{S}\left(\mathrm{H}_{2}\right) \cdot \mathrm{u}\left(\mathrm{C}_{2}, \mathrm{E}_{2}, \mathrm{H}_{2}\right)
$$


Utility at time $t, t=1,2$, is increasing in consumption $\left(C_{t}\right)$, education level $\left(E_{t}\right)$ and health $\left(H_{t}\right)$, and we assume that $u_{i}>0, u_{i i}<0, i=C_{t}, E_{t}, H_{t}, t=1,2$, where a subscript means the partial derivative. The introduction of education in the utility function represents the non-material benefits of education inspired by Michael (1973).

For simplicity, we ignore labor-leisure choice in the two-period model. $\rho$ is the time preference rate, but note that the utility in period two is also discounted with a factor $0<S<1$ that represents the probability of surviving the first period. This probability is increasing in the health level in the second period, but the returns from better health are decreasing with a higher health level, i.e., $S_{\mathrm{H}_{2}}>0, S_{\mathrm{H}_{2}, \mathrm{H}_{2}}<0$.

The health stock develops in the following way based on Grossman (1972),

$$
\begin{aligned}
& \mathrm{H}_{1}=\mathrm{h}_{0} \\
& \mathrm{H}_{2}=\mathrm{H}_{1}(1-\delta)+\mathrm{I}\left(\mathrm{IH}, \mathrm{TH}, \mathrm{E}_{2}\right)
\end{aligned}
$$

where the health stock increases in health investments $(I)$, but falls as the stock depreciates with time at a fixed depreciation rate, $\delta . h_{0}$ is the initial health, i.e., the health given at birth.

Investments in health are positively dependent on buying health services or medical care $(I H)$, spending time on healthy activities $(T H)$ and the education level, i.e., $I_{j}>0, I_{j j}<0, I_{j k}=0, j=I H, T H, E_{2}, k=I H, T H, E_{2}, j \neq k$. Note that we assume the cross derivatives of inputs in the investment function to be zero. ${ }^{6}$ As there are only two periods, no investments are made in the second period.

Education increases by spending time on schooling $(T E)$ and by monetary spending $(I E)$, but in a similar way as for health investments, the returns from time and monetary spending is falling

\footnotetext{
${ }^{6}$ This is a simplification. They are positive or negative depending on whether time and money are substitutes or complements in producing health.
} 
with the level of these input factors, i.e., $J_{l}>0, J_{l, l}<0, J_{l, v}=0, l=T E, I E, v=T E, I E, l \neq v .{ }^{7}$ As for health investments, we assume the cross derivatives to be zero. Finally, the depreciation of the education stock is set to zero as well.

$$
\begin{aligned}
& \mathrm{E}_{1}=\mathrm{e}_{0} \\
& \mathrm{E}_{2}=\mathrm{e}_{0}+\mathrm{J}(\mathrm{TE}, \mathrm{IE})
\end{aligned}
$$

As seen, we have chosen to explicitly model time investments in education and health separately from money investments. There is empirical evidence to suggest that the levels of time investments in these goods are considerable for the average individual (U.S. Bureau of Labor Statistics (BLS), 2012b).

Note that we ignore the direct impact from health to education in equation (3). Having a causality effect from health to education complicates the analysis, as education becomes a function of health, which is again a function of education, which is a function of health, etc. Including this causality would have made the relevant functions more elastic as the impacts of investments on the stocks and the utility function will be larger, but the qualitative conclusions from the policy analysis below will not change. ${ }^{8}$ This motivates a numerical model where we can see the impacts of this causality on the quantitative results.

Finally, the wealth of the consumer increases in income, where income is a function of time spent at work and the net-of-tax wage rate, $W_{t}$. In line with most literature, we assume that wages increase in education, i.e.,

$$
W_{t}=B\left(E_{t}\right)+\tau, \quad t=1,2,
$$

\footnotetext{
${ }^{7}$ A simplified version of this would be to assume that the monetary investments are linked to time such as a tuition fee per year of schooling. This means that time and monetary investments are used in a fixed proportion.

${ }^{8}$ Note, however, that we have indirect effects from health to education as the probability of surviving to the second period depends on health. This means that an increase in health increases the probability of collecting returns to an investment in schooling.
} 
where $\tau$ is an income subsidy (negative $\tau$ is an income tax), where $\mathrm{B}\left(\mathrm{E}_{1}\right)=\mathrm{w}_{0}$, i.e., it has a fixed value, and $B_{E}>0$ and $B_{E E}<0$ in period 2. The consumer spends her wealth on consumption goods (the numeraire good with a price normalized to unity), health services to a price $P$, and she also has to pay for education where $Q$ is the price per unit of the educational inputs. Based on this, we introduce an intertemporal budget constraint, where future money flows are discounted with the survival rate, and the interest rate is set equal to $r .^{9}$ Initial wealth is set to $n_{0}$, and $\omega$ is time available at each time period. Time in period 1 can be spent on work, health investments and education. Thus, this simple set up ignores the effects of health (being sick) on the available time budget. ${ }^{10}$

$(5) \mathrm{n}_{0}+(\omega-\mathrm{TE}-\mathrm{TH}) \mathrm{W}_{1}-\mathrm{C}_{1}-\mathrm{P} \cdot \mathrm{IH}-\mathrm{Q} \cdot \mathrm{IE}+1 /(1+\mathrm{r}) \cdot \mathrm{S}\left(\mathrm{H}_{2}\right) \cdot\left[\omega \mathrm{W}_{2}-\mathrm{C}_{2}\right]=0$

The consumer chooses $I H, I E, T H, T E$ and $C_{t}$ to maximize (1) with respect to the constraints (2)(5). This yield the following first order conditions (see Appendix 1 for details), where $\mathrm{A}=\omega \mathrm{W}_{2}-\mathrm{C}_{2}$, i.e., wealth addition in period 2:

(6) $\frac{1 /(1+\rho)\left[S\left(u_{E_{2}} J_{T E}+u_{H_{2}} \cdot I_{E_{2}} J_{T E}\right)+S_{H_{2}} I_{E_{2}} J_{T E} \cdot u\left(C_{2}, E_{2}, H_{2}\right)\right]}{u_{C_{1}}}-w_{0}+1 /(1+r)\left[S \cdot \omega B_{E_{2}} J_{T E}+S_{H_{2}} I_{E_{2}} J_{T E} \cdot A\right]=\tau$ (7) $\frac{1 /(1+\rho)\left[S\left(u_{E_{2}} J_{I E}+u_{H_{2}} \cdot I_{E_{2}} J_{I E}\right)+S_{H_{2}} I_{E_{2}} J_{I E} \cdot u\left(C_{2}, E_{2}, H_{2}\right)\right]}{u_{C_{1}}}+1 /(1+\mathrm{r})\left[S \cdot \omega B_{E_{2}} J_{I E}+S_{H_{2}} I_{E_{2}} J_{I E} \cdot A\right]=Q$ (8) $\frac{1 /(1+\rho)\left[S \cdot u_{H_{2}} I_{T H}+S_{H_{2}} I_{T H} \cdot u\left(C_{2}, E_{2}, H_{2}\right)\right]}{u_{C_{1}}}-w_{0}+1 /(1+r) \cdot S_{H_{2}} I_{T H} \cdot A=\tau$ (9) $\frac{1 /(1+\rho)\left[S \cdot u_{H_{2}} \cdot I_{I H}+S_{H_{2}} I_{I H} \cdot u\left(C_{2}, E_{2}, H_{2}\right)\right]}{u_{C_{1}}}+1 /(1+r) S_{H_{2}} I_{I H} \cdot A=P$

\footnotetext{
${ }^{9}$ In line with Becker (2007), we assume a full and fair annuity market that protects the individual against risk of running out of resources and risk against having unspent resources.

${ }^{10}$ Including sick time as in Grossman (1972), would increase monetary benefits from health investments as income in period 2 will increase. Thus, this gives an additional incentive to invest in health. However, it does not add to the qualitative impacts of policy instruments in this model as health investments already has a positive impact on expected income in period 2 through the survival function. Sick time is, however, included in the numerical model.
} 
(10) $\frac{u_{C_{1}}}{u_{C_{2}}}=\frac{(1+r)}{(1+\rho)}$

(11) $n_{0}+(\omega-T E-T H) W_{1}-C_{1}-P \cdot I H-Q \cdot I E+1 /(1+r) \cdot S\left(H_{2}\right) \cdot A=0$

The first terms on the left hand sides of equations (6) and (7) show the marginal benefits of increasing time and expenditures on education relative to the marginal benefits of increasing consumption in period one, thus giving the substitution between education investments and consumption expenditures. However, more education in period one also has an effect on income as it increases the wage rate in the second period, as well as expected wealth in the second period due to increased expected lifetime, represented by the last term on the left hand side of equations (6) and (7). In a similar way, equations (8) and (9) show the substitution between health investments and consumption and the income effect of increasing health investments. Finally, equation (10) shows that the marginal utility of consumption should be the same in both time periods adjusted for the relative difference between the interest factor and the time preference factor. In addition to these equations, the intertemporal budget constraint (11) also indicates the income effects of changes in exogenous variables.

To understand the interplay of education and health, we can use the equations above to get an intuition of the different effects of initial conditions and public policy. ${ }^{11}$ In particular, we want to study the effects of:
a. Increase in initial wealth $\left(d n_{0}>0\right)$
b. Increase in initial health $\left(d h_{0}>0\right)$
c. Subsidies to medical care $(d P<0)$
d. Subsidies to schooling $(d Q<0)$
e. Lower income taxation $(d \tau>0)$

\footnotetext{
${ }^{11}$ We do not do the full formal analysis in this paper as the model is quite complex, but instead give the intuition that is useful to understand the numerical model in Section 4. However, the equations for a total differentiation of the first order conditions are available from the authors.
} 
An increase in initial wealth $\left(n_{0}\right)$ (or, equivalently, a lump-sum income transfer) has an income effect, as it affects only the budget constraint, see (11). Thus, if health and education are normal goods, investments in both goods will increase. Better health will increase longevity, and the benefits of higher education will therefore be higher. However, it also gives an incentive to lower investments in education, as the individual does not have to invest in a higher wage rate to be able to buy the same quantity of goods as before. Therefore, the effect on education inputs is ambiguous.

How would people born with good health behave when it comes to investments in education and health compared to people less lucky at birth? To study this we consider an increase in initial health $\left(h_{0}\right)$. In this model, this will have an impact on the budget via the increase in expected lifetime, thus giving a positive income effect on both health and education. However, the substitution between health and consumption depends on what we assume about cross derivatives. Assume that $u_{E H}>0$ and $u_{C H}>0$, i.e., that the pair education and health, and the pair consumption and health are both complements in utility. ${ }^{12}$ From equation (6) and (7), we see that the effect on education investments is ambiguous. The reason is that a higher health level not only increases the benefits from education, but also from consumption. Both may actually increase, but not necessarily. This implies that the effects on education of a higher initial health are ambiguous and depends on magnitudes of the different effects.

Further, from (8) and (9) we see that the substitution between health and consumption goes in direction of lower health investments. This is due to the fall in the marginal benefits of these investments when the health stock is higher. Once again, the total effect on health investments is ambiguous for a higher initial health stock.

Let us now turn to policy measures and start with the effects of subsidizing medical care (health services). We see from (9) that a fall in the price of medical care, $P$, will increase health investments relative to consumption. A lower $P$ means that the left hand side of equation (9) has to decrease, and health investments will, therefore, go up. A fall in $P$ also gives a positive wealth effect. Thus, the income and substitution effects go in the same directions meaning that

\footnotetext{
${ }^{12}$ This is the assumption used in the simulation model in Section 4 below.
} 
subsidizing health care will increase consumption of medical care. The effect of time spent on healthy activities is ambiguous. On one hand, we get a substitution towards medical care as the relative prices change, but we also get an income effect that will work in the other direction. A lower price also means that one does not have to work as much as before to buy the same number of goods with the possibility that more time can be spent on health investments.

A lower price on medical care means that the relative prices of medical care and education change, giving a substitution effect that reduces demand for education investments. The positive income effect goes in the opposite direction. Thus, the effect on education investments is ambiguous. Effects on education from subsidizing medical care will also depend on cross derivatives. As above, if $u_{E H}>0$ and $u_{C H}>0$, we see from equations (6) and (7) that the effects on education investments are ambiguous. The reason is again that the benefits of both education and consumption will increase for better health with these assumptions.

Subsidizing schooling by reducing $Q$, gives a substitution effect where consumption is reduced relative to educational expenditures, see the first term on the left hand side of (7). In addition, this also gives a positive income effect as higher education increases the wage and the health level in the second period. Thus, both the substitution and income effects go in the direction of more investments in education expenditures. The effect of time spent on education is ambiguous as the substitution effect and income effect work in different directions.

Subsidizing schooling also has an effect on health investments. The relative prices between health and education change and reduce demand for health, but the income effect goes in the direction of higher demand for health. Again this also depends on the cross derivatives. If $u_{H E}>0$ and $u_{C E}>$ 0 , the effects on health investments are ambiguous, see (8) and (9).

There is another cost component of schooling, namely the alternative use of time spent on education, measured by the wage rate, $W_{t}$. Thus, lowering income taxation (increasing $\tau$ ) will increase the price on time spent on schooling, and will discourage education relative to consumption, see (6). Note however that there is also an income effect of lowering income taxation (increasing wages) that goes in the direction of spending more money on education 
investments, see (11). So the total effect on time spent on education is ambiguous. However, for education expenditures we only have the income effect, so they will increase.

Further, increasing $\tau$ has a similar effect on time spent on healthy activities as on time spent on education, see (8), i.e., the income and substitution effects go in different directions, giving an ambiguous result. For medical care, we have a positive income effect that gives a higher consumption.

Table 1 summarizes the results from the analysis, including the effects on consumption.

\begin{tabular}{|c|c|c|c|c|c|}
\hline Endogenous & \multicolumn{5}{|c|}{ Exogenous variables } \\
\hline variables & $\mathrm{dn}_{0}>0$ & $d h_{0}>0$ & $\mathbf{d P}<0$ & dQ $<0$ & $d \tau>0$ \\
\hline$C_{t}$ & + & + & ? & $?$ & + \\
\hline TE & ? & $?$ & $?$ & ? & ? \\
\hline IE & $?$ & $?$ & $?$ & + & + \\
\hline TH & + & $?$ & $?$ & $?$ & $?$ \\
\hline IH & + & $?$ & + & $?$ & + \\
\hline
\end{tabular}

Table 1: Behavioral implications from changes in exogenous variables.

\section{The numerical model}

In the numerical model, the consumer maximizes expected lifetime utility subject to balancing her intertemporal budget and equations that describe the probability of survival over time $\left(S_{t}\right)$ and the dynamics of the health $\left(H_{t}\right)$ and education $\left(E_{t}\right)$ stocks in the model. The choice variables in the model are consumption $\left(C_{t}\right)$, leisure $\left(L_{t}\right)$, monetary investments in health $\left(I H_{t}\right)$ and education $\left(I E_{t}\right)$ and time investments in health $\left(T H_{t}\right)$ and education $\left(T E_{t}\right)$ at each point in time $t$ (or $t t$ ). In the numerical implementation, we solve the model over a 110-year time horizon using a five-year time step, starting at age $20 .^{13}$

\footnotetext{
${ }^{13}$ In the model notation, the names of all endogenous variables are capitalized and all exogenous parameters are lower case or Greek letters.
} 


$$
\max _{C, L, I H, I E, T H, T E} U=\sum_{t=1}^{T} S_{t} /(1+\rho)^{t-1}\left[\tau_{e} E_{t}^{\rho_{h z}}+\tau_{h} H_{t}^{\rho_{h z}}+\left(1-\tau_{e}-\tau_{h}\right)\left(\left(Z_{t}^{\zeta}-Z_{0}^{\zeta}\right) / \zeta\right)^{\rho_{h z}}\right]^{1 / \rho_{h z}}
$$

subject to the sub-utility function,

$$
Z_{t}=\left((1-S I)\left(C_{t} / C_{0}\right)^{\kappa}+S I\left(L_{t} / I_{0}\right)^{\kappa}\right)^{1 / \kappa}
$$

the survival probability,

$$
S_{t}=1-e^{-\phi H_{t}^{\theta}}
$$

the wealth constraint,

$$
\begin{gathered}
n_{0}+\sum_{t}\left\{\left[\omega-L_{t}-p t e_{0 t}\left(T E_{t}-1\right)-p t h_{0 t}\left(T H_{t}-1\right)+\left(\left(H_{t} / h_{0 t}\right)^{\beta}-1\right)\right] W_{t}+\right. \\
\left.b_{t}-C_{t}-p h_{0 t}\left(I H_{t}-1\right)-p e_{0 t}\left(I E_{t}-1\right)\right\} S_{t} /(1+r)^{t-1}=0
\end{gathered}
$$

the health stock transition,

$$
H_{t}=h_{0 t}+\sum_{t t \leq t} h_{0 t t}\left(\left(\mathrm{E}_{t t} / e_{0 t t}\right)^{\alpha} I H_{t t}^{\gamma} T H_{t t}^{v}-1\right)(1+t t / T)^{\varepsilon}\left(1-\delta_{h}\right)^{t-t t}
$$

and the wage/education transition:

$$
E_{t}=e_{0 t}+\sum_{t t \leq t} e_{0 t t}\left(\left(H_{t t} / h_{0 t t}\right)^{\mu} I E_{t t}^{\eta} T E_{t t}^{\xi}-1\right)(1+t t / T)^{\psi}\left(1-\delta_{e}\right)^{t-t t}
$$

Finally, we assume that the wage evolves over time solely as a function of the education stock, thus: $W_{t}=E_{t}$.

In equation (12), lifetime utility depends on the level of the education stock, the level of the health stock and the level of the full consumption good $\left(Z_{t}\right)$ above a subsistence level $\left(z_{0}\right) . \zeta$ controls the elasticity of $Z$ with respect to income. Period utility at time $t$ (the expression in square brackets) is discounted at the pure rate of time preference $(\rho)$ as well as probability of survival to time $t$. Period utility follows a constant-elasticity-of-substitution (CES) form, where 
$\tau_{e}$ and $\tau_{h}$ (taking on non-negative values such that $\tau_{e}+\tau_{h} \leq 1$ ) are preference parameters on the direct contributions of education and health to utility respectively. $\rho_{h z}$ is a preference parameter that controls the elasticity of substitution between education, health and full consumption. This functional form implies that the cross derivatives on $E_{t}, H_{t}$ and $Z_{t}$ are all assumed to be positive, as discussed in the two-period model in Section 3.

Full consumption in each time period $\left(Z_{t}\right)$ is produced by combining leisure $\left(L_{t}\right)$ and consumption goods $\left(C_{t}\right)$ via a CES function as described in equation (13). We use the calibrated shares format for CES functions (Rutherford, 2002). The arguments for the consumption goods are normalized to unity by dividing by their benchmark levels, $C_{0}$ and $I_{0}$ at age 50 . In this case, $S$ (where $0 \leq S l \leq 1$ ) can be interpreted as the value share of leisure in full consumption (at age 50 ) when leisure time is valued at the benchmark wage rate. $\kappa$ controls the elasticity of substitution between leisure and market consumption.

The probability of survival to year $t, S_{t}$, is functionally related to the individual's level of health stock in (14), where $\phi$ and $\theta$ control the shape of the hazard function.

The individual must maintain an intertemporally-balanced budget over her lifetime see (15), where income comes from existing initial assets at the beginning of life $\left(n_{0}\right)$, wage income, and any transfers to households $\left(b_{t}\right)$. Wage income is expressed as the amount of the individual's benchmark total time endowment $(\omega)$ that is not devoted to leisure. In counterfactual experiments, the individual's effective time endowment will also depend on how levels of time investments in health and education vary and how the individual's health status varies, affecting the number of sick days required. In equation (15), the three terms corresponding to these effects appear within the square brackets on the left-hand side of the equation. ${ }^{14}$ The units of investments in education $\left(T E_{t}\right.$ and $\left.I E_{t}\right)$ and health $\left(T H_{t}\right.$ and $\left.I H_{t}\right)$ have been chosen such that these

\footnotetext{
${ }^{14}$ In each case, the relevant endogenous variable responsible for producing the effect $\left(T W_{t}, T H_{t}, H_{t}\right)$ is divided by the levels these variables take on in the benchmark equilibrium in the calibrated model $\left(t w_{0 t}, t h_{0 t}, h_{0 t}\right)$. Thus, these terms take on a value of unity in the benchmark equilibrium. When unity is subtracted from these terms, as it is in these expressions, they make no contribution to the individual's budget.
} 
variables are equal to unity in the benchmark equilibrium of the model. Similarly, the health stock term in the function that describes the number of sick days required (third additive term in square brackets) has been divided by the benchmark level of the health stock $\left(h_{0 t}\right) . \beta$ is the elasticity of sick days with respect to the health stock. Because unity is subtracted from each of these terms, they do not contribute to household's budget in the benchmark equilibrium. In counterfactual experiments, their values capture added costs or savings from changing these activity levels relative to the benchmark. The same logic applies to the modeling of the money investment goods in the budget constraint. $p t h_{0 t}, p t e_{0 t}, p h_{0 t}$ and $p e_{0 t}$ capture the benchmark level of expenditures on the different investment goods. Time is valued at the individual's wage rate $\left(W_{t}\right)$.

Equation (16) describes the transition of the health stock over the life cycle. Health depends on the levels of past investments in time and money dedicated to health production as well as the individual's education stock. $v, \gamma$ and $\alpha$ govern the respective productivities of these different channels in producing better health. Finally, equation (17) describes how wages and the education stock evolve over time. The variables depend on the levels of past investments in time and money dedicated to education, but also on the health stock. $\xi, \eta$ and $\mu$ govern the respective productivities of these different channels in producing better health. Both the health and education stock equations contain time-trend terms $\left((1+t t / T)^{\varepsilon}\right.$ and $\left.(1+t t / T)^{\psi}\right)$ that allow the productivity of investments in these stocks to vary with age. For example, the decline in health or human capital may be more difficult to abate as one becomes older. As in equation (15), the terms that describe the effects of the endogenous levels of education and health stocks and investment goods on the stocks in (16) and (17) have been constructed in a manner such that they make no contribution to the equation in the benchmark equilibrium and when the stocks follow their benchmark levels $\left(h_{0 t}\right.$ and $\left.e_{0 t}\right)$. Thus, these terms are interpreted in the counterfactual experiments as the additional gains or losses to the stocks due to changing the levels of these variables. Finally, the health and education stocks are subject to depreciation, where $\delta_{h}$ and $\delta_{e}$ are the constant depreciation rates.

A full listing of the model variables and parameters used in the numerical model is included in Appendix 2. 
There are a few important differences in the structure of the numerical model and the analytical model presented in the previous section of the paper. There is a leisure activity in the numerical model that competes for use of the individual's time endowment with labor supply and time investments on health and education in the model. In addition, sick time is introduced which alters the total time endowment. The level of the education stock also depends on the level of the health stock in the numerical model so there is potential for feedback effects moving from health to education as well as from education to health. These features of the numerical model may be important to the quantitative significance of the results of our simulation experiments but should not influence the qualitative predictions relative to those produced by the analytical model.

The model is summarized in Figure 1 below.

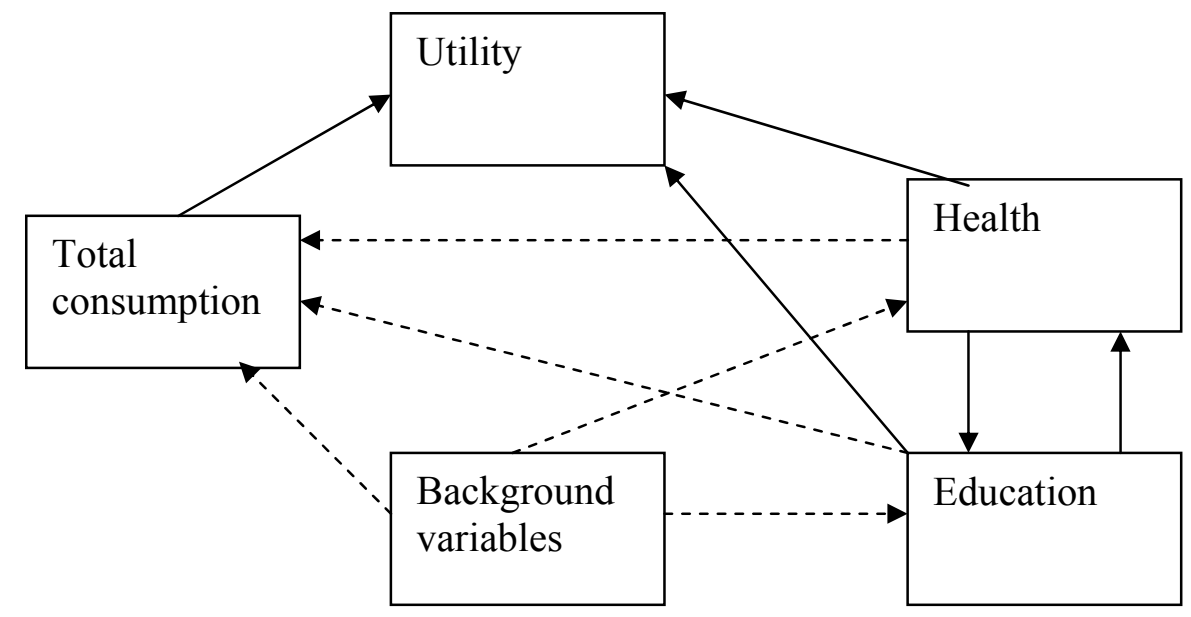

Figure 1: A flow diagram of the model.

The linkages from education to health and from health to education as described above are illustrated in the figure by means of solid arrows. In addition, there are also indirect effects from education and health to leisure and consumption goods, as well as from background characteristics to health, education and consumption as are shown in Figure 1 as dashed arrows:

- Individual specific background variables such as the time preference rate and initial wealth give indirect effects on health, education and total consumption. 
- Good health reduces the time being sick, which means that there is more time available for schooling, as well as for working, leisure activities and healthy activities.

- More education increases the wage level and therefore affects consumption.

\section{Calibration Procedure}

The calibration procedure builds off the one developed by Murphy and Topel (2006). That study did not attempt to model endogenous investment in health or education as we do here. Rather, they calibrated a life-cycle consumption model to exogenous trajectories of $H_{t}$ and $S_{t}$. In the Murphy-Topel procedure, $S_{t}$ is chosen to reproduce data on mortality rates. $H_{t}$, which is not observed directly, is calibrated to fit consumption and earnings data for an average individual in the United States given the structural assumptions in the model. The other key parameters in the model are calibrated to imply a specific value for the consumer's willingness to pay for marginal reductions in the probability of death (their value of a statistical life or VSL). We calibrate the model based on data covering residents of the United States from the study of Murphy and Topel (2006), from the U.S. Bureau of Labor Statistics (BLS) (2012a,b;2013) and U.S. life tables (Arias, 2012).

We follow this procedure to calibrate the model to exogenous trajectories for $S$ and $H$ and then go on to describe a new method for calibrating the features of the model related to the endogenous health and education stocks. Specifically, using the calibrated version of the model with exogenous levels of these stocks, we calculate the shadow prices associated with a marginal increase in the levels of the health and education investment goods $\left(I H_{t}, I E_{t}, T H_{t}\right.$ and $\left.T E_{t}\right)$.

These are, by definition, the effective prices of the investment goods $\left(p h_{0 t}, p e_{0 t}, p t h_{0 t}\right.$ and $p t e_{0 t}$ respectively) required to replicate the benchmark trajectories in the model. We normalize the benchmark levels of the investment goods in the model to unity and calibrate key parameters influencing the effectiveness of these investments with the objective of producing the best fit between the predictions on expenditures on these goods generated by the model and data on monetary and time expenditures on these goods as well as consumption expenditures. The details of the calibration procedure are described in Appendix 3, while the calibrated parameter values are shown in Table 2. 
Our calibration strategy responds to the fact that the empirical literature on the productivity of health and education investments and the interactions between them (summarized in section 2) is still inconclusive. A number of the structural parameters governing the productivity of health and education investments as well as their interactions do not have close analogs in the empirical literature or do not have values that are known with any precision. Our calibration strategy chooses the values for these parameters that best allows the structure of our model to fit data on investment levels. ${ }^{1516}$

\subsection{Calibration Results}

Figure 2 depicts the benchmark trajectories for consumption $(C)$, the individual's health stock $(H)$ and full income, i.e., total time endowment valued at the wage rate $(\omega \times W)$, over the life cycle. The consumption path is chosen to match BLS data on expenditures over the life cycle - rising in early life, peaking and then falling through later years. ${ }^{17}$ The individual's health stock remains roughly constant through early and mid-life and then declines as the individual approaches old age. Full income - including both monetary income sources as well as the value of leisure time rises until retirement (assumed to be age 65) - after which point it is assumed that retirement benefits replace half of projected wages based on the calibrated wage profile.

\footnotetext{
${ }^{15}$ It is important to emphasize that our calibration strategy (as well as the Murphy-Topel model upon which it is based) is premised on the idea that households make choices regarding consumption and investment in a manner consistent with unrestricted rational choice without uncertainty. Moreover, it assumes that they do so within the parameters of the structural assumptions of the model described in the previous section. This has two important implications. First, our ability to establish the causal effects of income, education and health as well as investments in education and health is conditional on this structure. Second, we do not model the complications introduced by, for example, public schooling or health care. We also do not account for the fact that individuals learn about realizations of their health state or job prospects over time. As a result, our calibration is vulnerable to bias to the extent that these features systematically influence the data on consumption and investments that we use. We view the incorporation of these complications as important steps for future research.

${ }^{16}$ We calibrate the expenditures of time and money on health and education investments produced by the benchmark model to data on observable measures of expenditures in these categories. In the case of monetary health expenditures, we calibrate to a measure of medical expenditures. In the case of time investments in education, we calibrate to time survey data on time spent of formal schooling. In both cases, a challenge with our calibration approach is that the data are not comprehensive, and therefore likely understate the size of the full investments household make. This leads to the potential for our estimate of the model parameters to understate the importance of these investments in generating health and educational outcomes. It would be difficult to take a constructive approach to calibration, where one tries to account for all of these channels individually and produce an aggregate measure as an input to our model. And assigning parameter values directly from empirical estimates also seems difficult due to the inconclusiveness of the empirical literature and the difficulty in mapping reduced-form parameters estimates in the literature to the structural parameters required in our model.

${ }^{17}$ See U.S. Bureau of Labor Statistics (2012a, 2013) .
} 


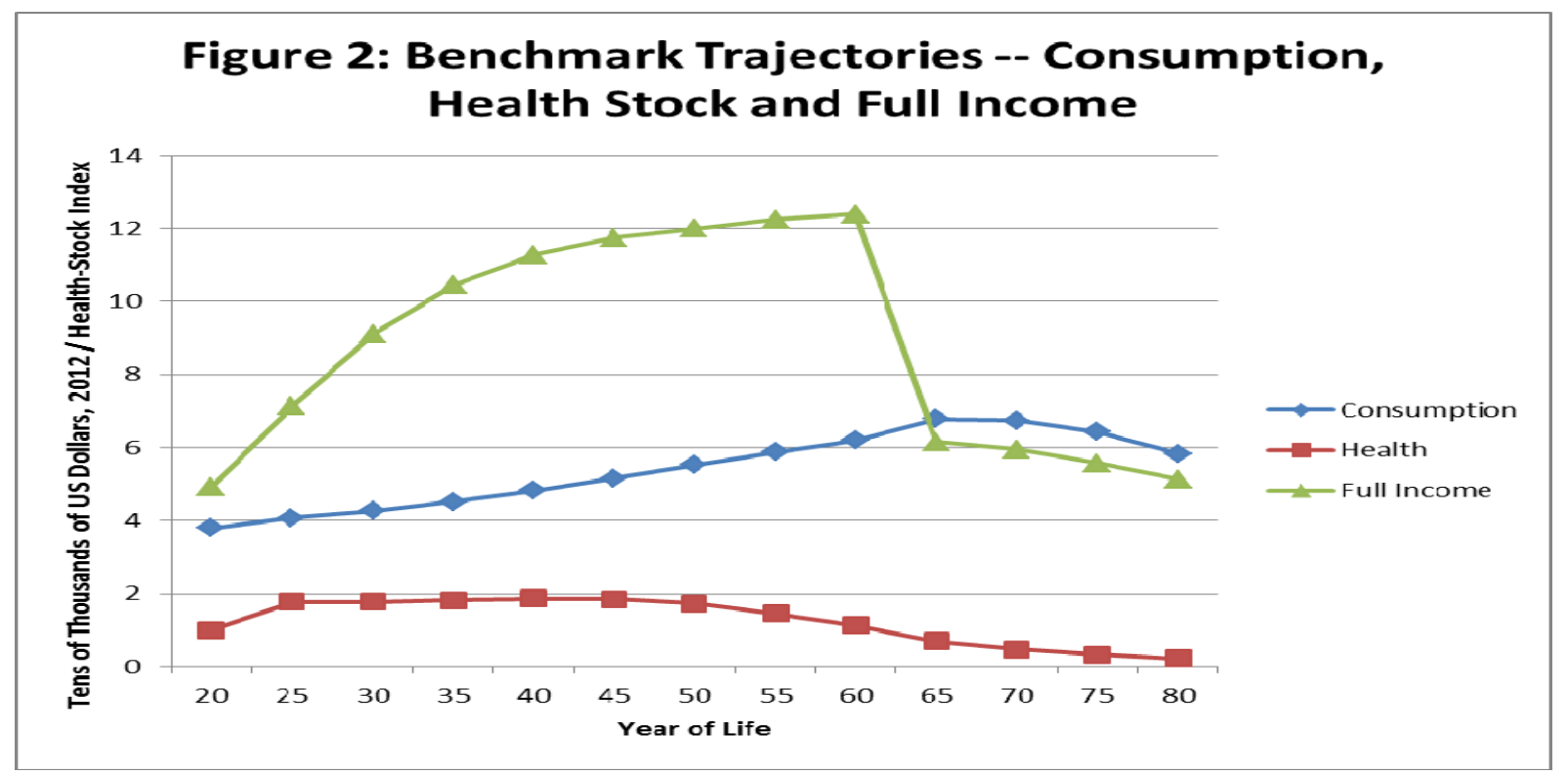

Figure 3 depicts the calibrated trajectories for expenditures on the various health and education investment goods in the model - monetary expenditures on health (ph0), time expenditures on health (pth0), monetary expenditures on education (pe0) and time expenditures on education (pte0). Investments in health peak around age 60 and then remain roughly constant until the end of life, while investments in education are weighted toward the beginning of life and then decline after age 35. Monetary and time investments on health and education are calibrated to data. Empirically, the average individual spends far more on health investments than on education and education investments are weighted toward the beginning of life. The calibration of the model aims to capture both of these features of the data. 


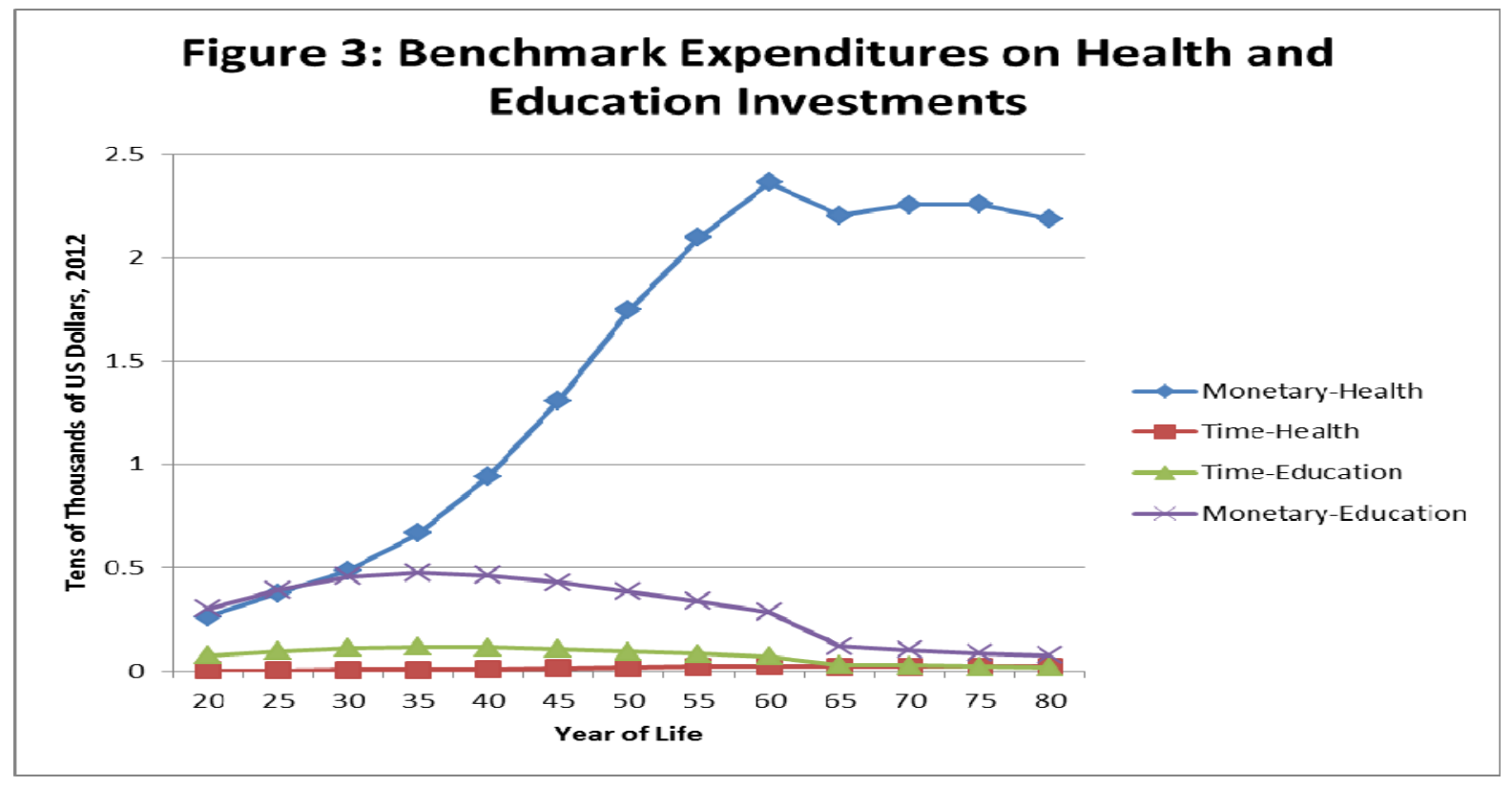

Our calibration of the education investments is based only on data for expenditures of time and money on education from ages 20-25 because measurable expenditures of formal education after this age are quite small for a representative individual in the data. Similarly, the model agent is restricted to choosing the levels of these investments from ages 20-25 in the counterfactual experiments. The reason for this is that, conceptually, the measures of investments in education in our model should be interpreted as all investments that enhance human capital - including formal and informal education as well as job training and skills acquisition. While it is reasonable to assume that the majority of these investments take the form of formal education (for which we have data to calibrate the model to) early in life, this is not a reasonable assumption later in life. This is the rationale for restricting the calibration to years 20-25. It also explains the significant investments in education after this age predicted by the model - these are informal sources of education. 


\begin{tabular}{llr}
\hline Model Parameters & Value \\
\hline$\phi$ & slope term in survivorship function & 3.6649 \\
$\theta$ & exponent term in survivorship function & 1.2104 \\
$\beta$ & elasticity of health in sick days & 0.0131 \\
$\gamma$ & parameter for productivity of money investments in health & 0.0342 \\
$\eta$ & parameter for productivity of money investments in education & 0.0202 \\
$\tau_{e}$ & share parameter of direct effects of education on utility & 0.0110 \\
$\tau_{h}$ & share parameter of direct effects of health on utility & 0.0136 \\
$\alpha$ & parameter for productivity of education stock in health & 0.0076 \\
$\nu$ & parameter for productivity of time investments in health & 0.0003 \\
$\mu$ & parameter for productivity of health stock in education & 0.0208 \\
$\xi$ & parameter for productivity of time investments in education & 0.0050 \\
$\varepsilon$ & elasticity of time trend in productivity of health investments & -1.8416 \\
$\psi$ & elasticity of time trend in productivity of education investments & -1.5037 \\
$\rho_{h z}$ & elasticity of substitution between health, education and full consumption in utility & -1.3434 \\
$c_{0}$ & benchmark consumption at year 50 & 6 \\
$l_{0}$ & benchmark leisure time at year 50 & 0.5 \\
$z_{0}$ & subsistence level of full consumption & 0.1 \\
$r$ & market interest rate & 0.04 \\
$\rho$ & pure time rate of preference & 0.02 \\
$\sigma$ & intertemporal elasticity of substitution & 0.8 \\
$s l$ & Value share of leisure in full consumption & 0.5 \\
$\omega$ & Time endowment & 1 \\
$\delta_{h}$ & depreciation rate of new investments in $H_{t}$ & 0.05 \\
$\delta_{e}$ & depreciation rate of new investments in $E_{t}$ & 0.01 \\
$\zeta$ & $(\sigma-1) / \sigma$ & -1 \\
$\kappa$ & $\left(\sigma_{z}-1\right) / \sigma_{z}$ where $\sigma_{z}$ is the elasticity of substitution between leisure and consumption & \\
& in full-consumption bundle & \\
\hline & & \\
& & 0.25 \\
\hline
\end{tabular}

Table 2: Calibrated Parameter Values

A few observations regarding the calibration results are in order. We find the money investments in health and education ( $\gamma$ and $\eta$ ) yield the largest impacts on their respective stocks. Time investments for both health and education ( $v$ and $\xi$ ) are less impactful. The effect of the health stock on education $(\mu)$ is positive but significantly weaker than is the effect of direct investments on health. The effect of education on health $(\alpha)$ is quite weak in our calibration. Both health and education make similarly large contributions to utility directly $\left(\tau_{h}\right.$ and $\left.\tau_{e}\right)$. The productivity of 
health and education investments ( $\varepsilon$ and $\psi$ ) fall as the individual ages at a similar rates. The calibration implies an elasticity of substitution (a function of $\rho_{h z}$ ) between the health, education and consumption arguments in the utility function of approximately 0.4 . Thus, the three goods are significantly stronger complements than would be implied by a Cobb-Douglas preference function for example.

\section{Policy Experiments}

Our main interest is in understanding of how the different policy interventions related to health, education and general well-being affect individual choices regarding investments in health, education and overall welfare. In line with this, we have designed a number of policy scenarios similar to those used in the two-period model that we can analyze by solving for the optimal behavior using our calibrated numerical model.

The policy scenarios are stylized and not intended to reproduce the details of any particular, realworld policy proposal. They are designed to accomplish two objectives. First, they reflect the general notion that policymakers view interventions in household education, health or wealth accumulation as important strategies to affect household well-being. To the extent that our analysis can illustrate how targeting these different channels leads to different outcomes, we can help policymakers better achieve their stated goals. For example, health policies may lead to the intended improvements in health outcomes but may also produce the unintended consequences of reducing of household investments in education or material consumption (see Table 1), a fact that policy design may wish to take into account. Second, the fact that the different policy interventions described in our scenarios engage the different causal mechanisms in our model to different degrees allows us to diagnose the extent to which each is responsible for producing our main results. Thus, by comparing the outcomes of the different policy scenarios, we can learn about the importance of and the interactions between these different channels in a quantified model. 


\subsection{Policy Scenarios ${ }^{18}$}

Initial Wealth Transfer - we increase the present-value of individual wealth by $1 \%$ of the benchmark level by increasing the value of $n_{0}$ in equation (15).

Medical Care Subsidy - we introduce a proportionate reduction in the price of medical care at all time periods $\left(p h 0_{t} \text { in equation }(15)\right)^{19}$.

Education (Tuition) Subsidy - we introduce a proportionate reduction in the price of education at all time periods $\left(p e 0_{t} \text { in equation }(15)\right)^{20}$.

Income Tax Reduction - we introduce a proportionate increase in the after-tax wage at all time periods $\left(W_{t}(1+w s)\right.$ in equation (15) where $w s$ is a constant, positive subsidy rate or, equivalently, the negative of the income tax rate reduction).

The initial wealth transfer serves as a benchmark against which to judge the results of the alternative policy interventions in our analysis. Individuals in our model exhibit perfect foresight and perfect information. Therefore, a lump-sum wealth transfer yields the largest possible improvement in well-being by assumption. The three alternative policies we consider all feature restrictions on how the individual may benefit from them; households must engage in medical care, education or labor supply to collect the subsidies. The medical care and education subsidies are intended to model direct interventions in improving health and human capital outcomes. We also focus on the income tax reduction because it is a more common strategy used by governments to affect the material wealth of targeted households than a lump-sum wealth transfer. It also presents household with different incentives to invest in consumption, education and health as we shall see.

To make these alternative policies comparable to the wealth-transfer benchmark, the subsidy rate or tax-rate reduction in each case is calculated to ensure that the lifetime present value of the

\footnotetext{
${ }^{18}$ Note that we do not study how the transfers are financed, i.e., we assume that the individual is unaffected by the public authorities budget constraints.

${ }^{19}$ Similar to $P$ in the two-period model.

${ }^{20}$ Similar to $Q$ in the two-period model.
} 
policy is equal to the value of the initial-wealth-transfer policy at the household's benchmark levels of demand for all goods in the consumption bundle. Naturally, the household will adjust these demands in response to the policy interventions but - were they to choose their benchmark consumption bundle in the counterfactual - they would receive an equivalent value monetary transfer.

We also study one policy measure, which does not allow for a welfare comparison with the other policy scenarios, an increase in the level of the initial health stock assumed in the model.

Initial Health Increase - we introduce a 1\% increase in the size of the initial health stock from benchmark levels through a change to $h_{0 t}$ in equation (16). Note that this means an increase in health at age 20 .

The purpose of this scenario is to explore the role that early-life differences in health have on future outcomes as much of the recent empirical literature on health and education outcomes focuses on the role early-life conditions, see Section 2 above. Moreover, this scenario represents a health-intervention policy that does not distort relative prices in the same way as the medical care subsidy. Therefore, we can learn about the impact of this distortion by comparing the pattern of investment changes delivered by the two experiments. Thus, while we cannot make welfare comparisons between this scenario and the others we consider, we can use it to conduct an analysis of the qualitative differences between the policies. ${ }^{21}$

\section{Simulation Results}

\subsection{Effects on investments}

We now discuss the changes in the levels of investment in health and education under the different policies, described in Figures 4-8. The changes reported in the figures are percentages of

\footnotetext{
${ }^{21}$ One final note regarding the design of the policy scenarios is in order. The prices of the investment goods should be interpreted holistically. That is, conceptually they reflect the cost of utilizing all of the channels - both marketbased and non-market - that households have at their disposal to affect health or educational outcomes. In the policy analysis, we focus on subsidies to formal education and medical care, which represent subsets of the cost categories covered by the prices in the model. Thus, one should imagine these subsidies lowering the cost of some investment options in the bundles of all investments, and lowering the overall cost of these bundles to the extent that these options are utilized.
} 
the benchmark levels of the model variables in the initial calibration of the model. Each figure reports changes in time investments in health $(T H)$ and education $(T E)$ as well as monetary investments in these two stocks ( $I H$ and $I E$, respectively). While the model is solved over a 110year time horizon, the horizon reported in the figure is restricted to models years $20-80$ as expected life length to which the model is calibrated is 78 years. Note, once again, that the choices of IE and TE are restricted to model years 20-25, thus percentage changes in these levels are only depicted for year 20 in the figures.

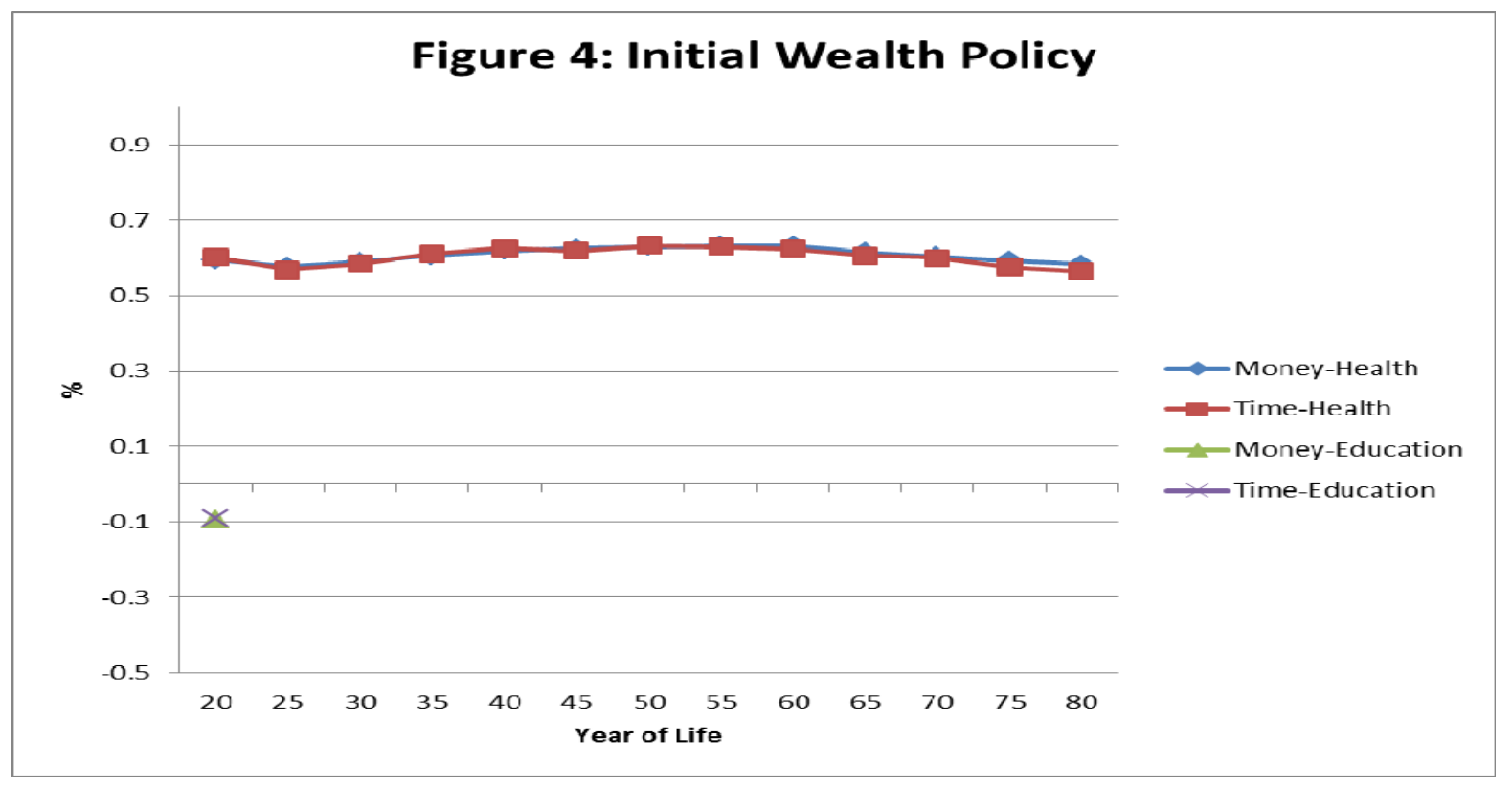

Figure 4 describes the results of the initial wealth transfer policy. Time investments in health rise under the wealth transfer program. When wealth rises, higher health and life extension are required to enjoy the higher level of material consumption now possible. Time and money investments both produce health and the relative prices of these investments are not directly affected by the policy intervention. As a result, they rise by comparable amounts. Further, investments in education fall modestly. As noted in our discussion of the two-period model, the initial wealth transfer relieves some of the motivation to invest in education - to increase consumption through higher wages - because higher levels of consumption are possible at the same wages after the wealth transfer. Moreover, the increase in the health stock resulting from higher investments in health tends to increase wages and education due to the feedback mechanism from health to education in the model, further reducing the incentive to invest directly 
in education. Thus, while there is a positive income effect in the model that works to increase education levels, these substitution effects appear to offset it at our calibration, leaving the levels of the education stock under this policy essentially unchanged from benchmark levels. ${ }^{22}$

The wealth-transfer scenario functions as a benchmark from a policy perspective, revealing the pattern of investments that optimize lifetime utility when given additional resources. The experiment reveals that raising consumption (not in the graph) and health levels are the strongest responses for the individual in our calibration. Thus, the model suggests that interventions that pair improvements in health and material living standards are most likely to promote overall individual well-being. Alternatively, our model suggests that policies that promote wealth accumulation are likely to raise individual health levels and leave human capital levels largely unchanged as a byproduct.

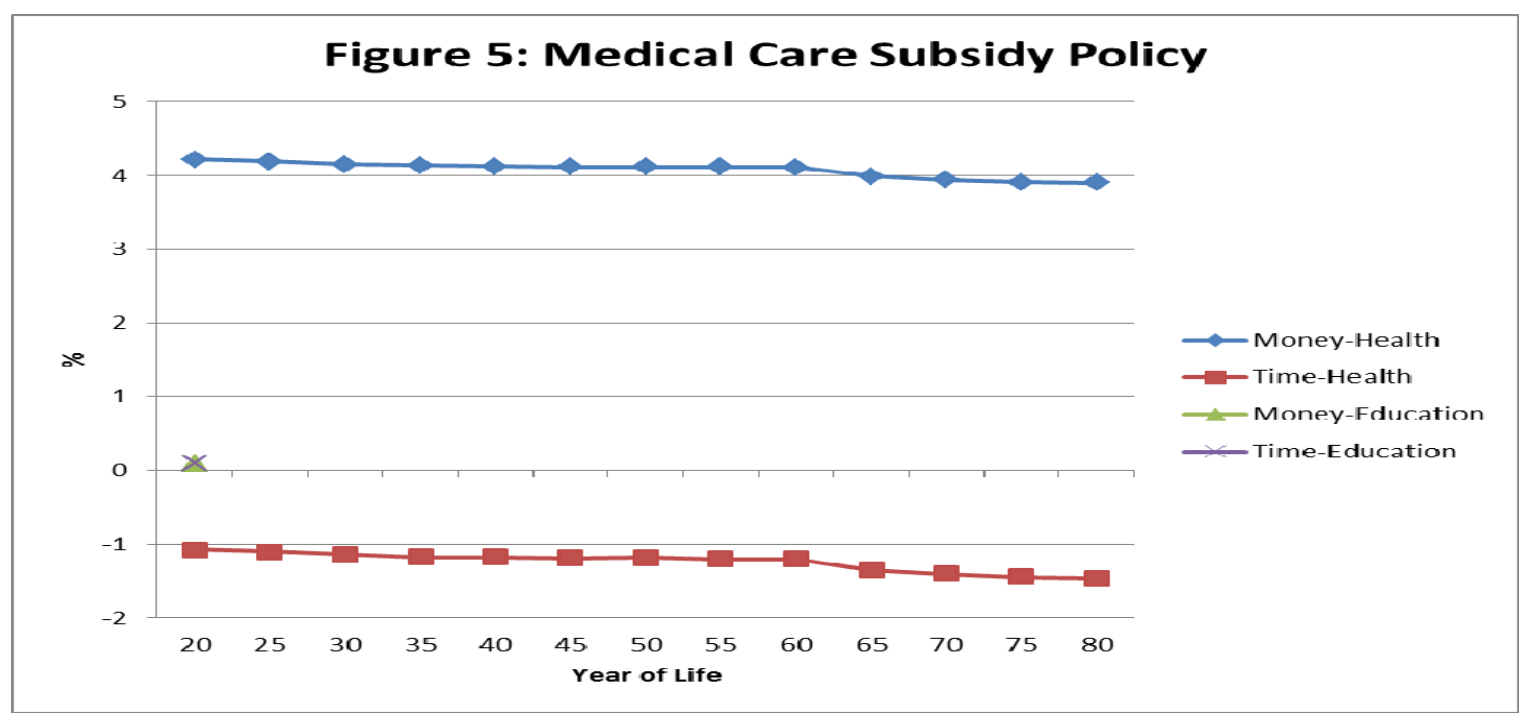

Figure 5 shows the results of the medical care subsidy. Naturally, the subsidy stimulates demand for medical care, thus monetary investments in health rise under this policy. Time investments in health fall due to the substitution effect between money and time investments in health. Investments in education rise slightly as the overall cost of living falls with the medical care

\footnotetext{
${ }^{22}$ Our result stands in contrast to that of Galama and van Kippersluis (2015) who find that wealthier individuals always place a higher value investment in education. A key difference in assumptions in their analysis from our model is the health and education stocks both enter the production functions for investments in health and education. This leads to the potential for stronger self-reinforcement effects between health and education investments than are present in our model and could explain the difference in our results.
} 
subsidy, increasing the returns to working and investing in higher wages. This result contrasts with the reduction in education investments under the wealth-transfer policy, where relative prices remain unchanged. While the analytical model demonstrates that all investments goods with the exception of medical care - exhibit negative substitution effects and positive income effects, the simulation results suggest that the income effects dominate for the education investments, but not for time investments in health. Increased spending on medical care comes largely at the expense of material consumption levels, which fall over most of the lifecycle for the individual.

From a policy perspective, the medical care subsidy causes the individual to over-invest in medical care and education while under-investing time in health maintenance and material consumption relative to the wealth-transfer benchmark in which the individual chooses its consumption and investment responses with complete flexibility.

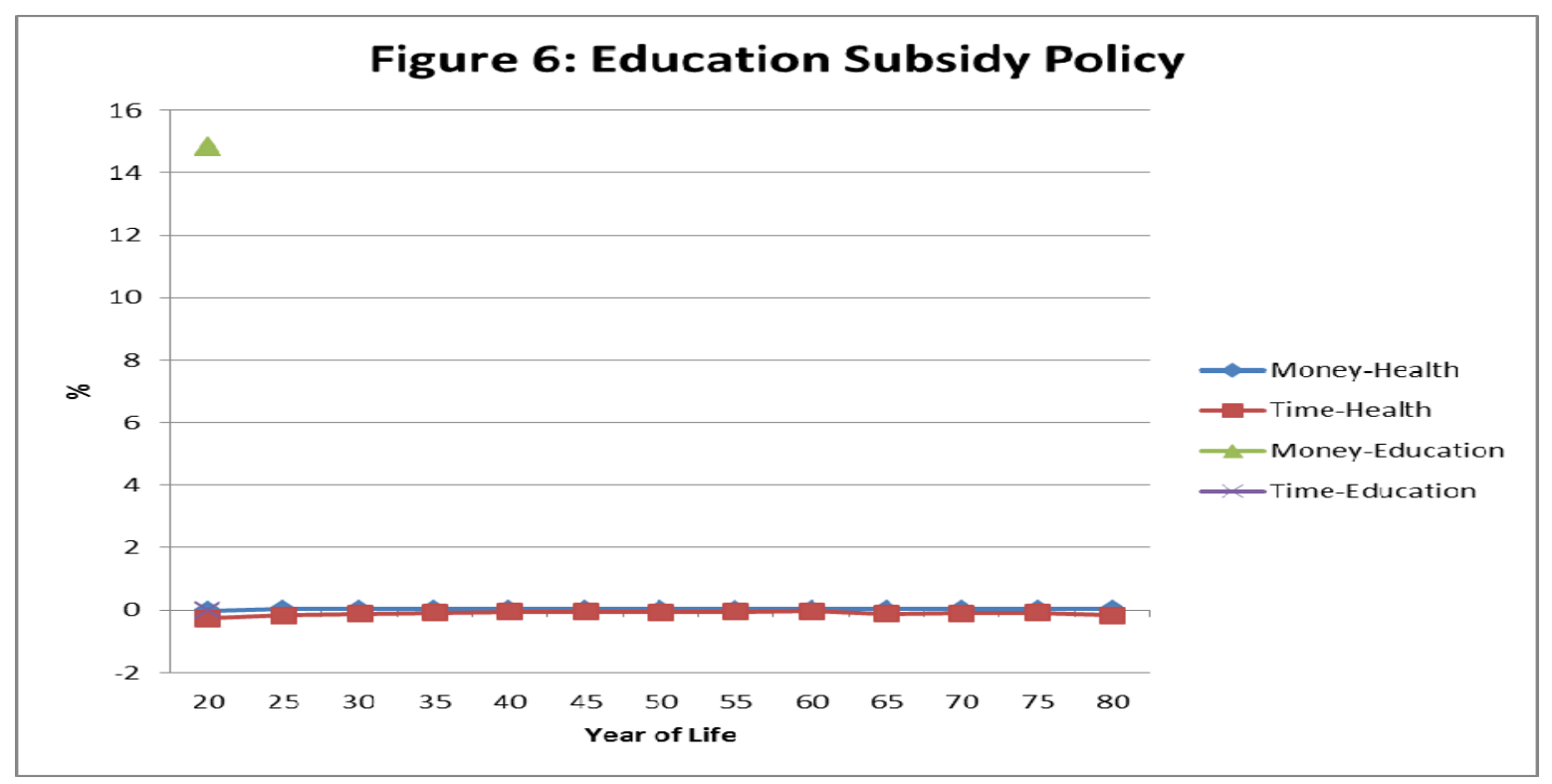

The results of the education (or tuition) subsidy are shown in Figure 6. The subsidy stimulates the demand for money investments in education. Other investments - time and money in health as well as time in education - are little changed from benchmark levels under this policy. While there are negative substitution effects and positive income effects for all investments goods except for money investments in education, the simulations suggest that these effects roughly 
cancel out for all three other investment goods. The education subsidy causes an over-investment in education and under-investment in health and material consumption.

An income tax reduction is a common policy option for improving well-being but one that features a distortionary effect on the opportunity cost of time spent in labor that is not present in our wealth-transfer policy scenario. As seen in Figure 7, increasing the after-tax wage has the effect of increasing monetary investments in both health and education. Time investments in health rise modestly while time investments in education fall modestly. The increase in the wage makes monetary investments more affordable and time investments less affordable because the opportunity cost of time has risen. Greater income that comes with higher wages means that better health and longer life expectancy is required to take advantage of the higher level of consumption possible. This may explain why slightly more new investment is directed at health than at education. Finally, the analytical model predicts that money investments in both health and education should rise - with both positive substitution and income effects - under the increase in wage while time investments may rise or fall. The simulations are consistent with these predictions - with money investments rising substantially while time investments change very little.

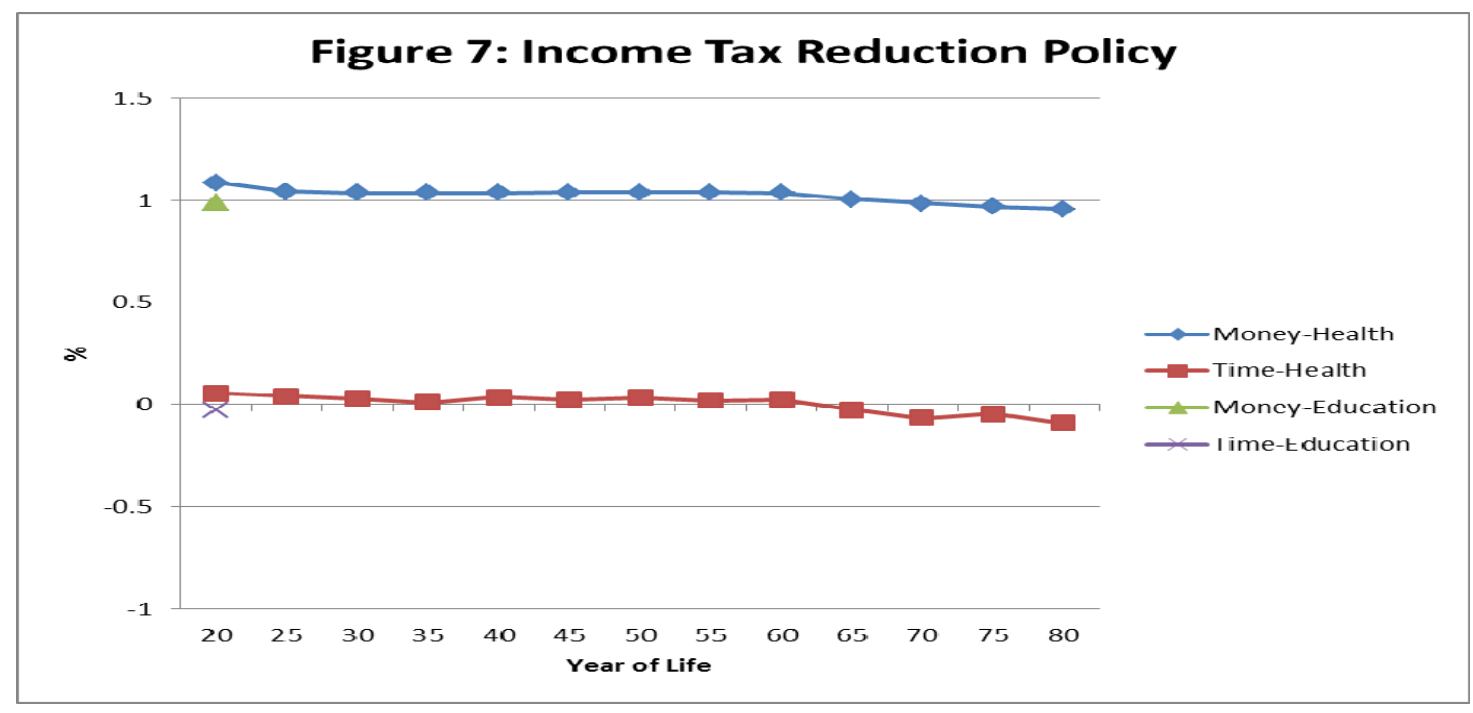

Relative to our wealth-transfer benchmark calculation, the income tax reduction generates similar but somewhat larger increases in monetary investments in health and education as well as 
material consumption, a natural consequence of the fact that the individual has full discretion in how to use the additional proceeds from the tax cut. It differs primarily in the wedge it drives between monetary and time investments.

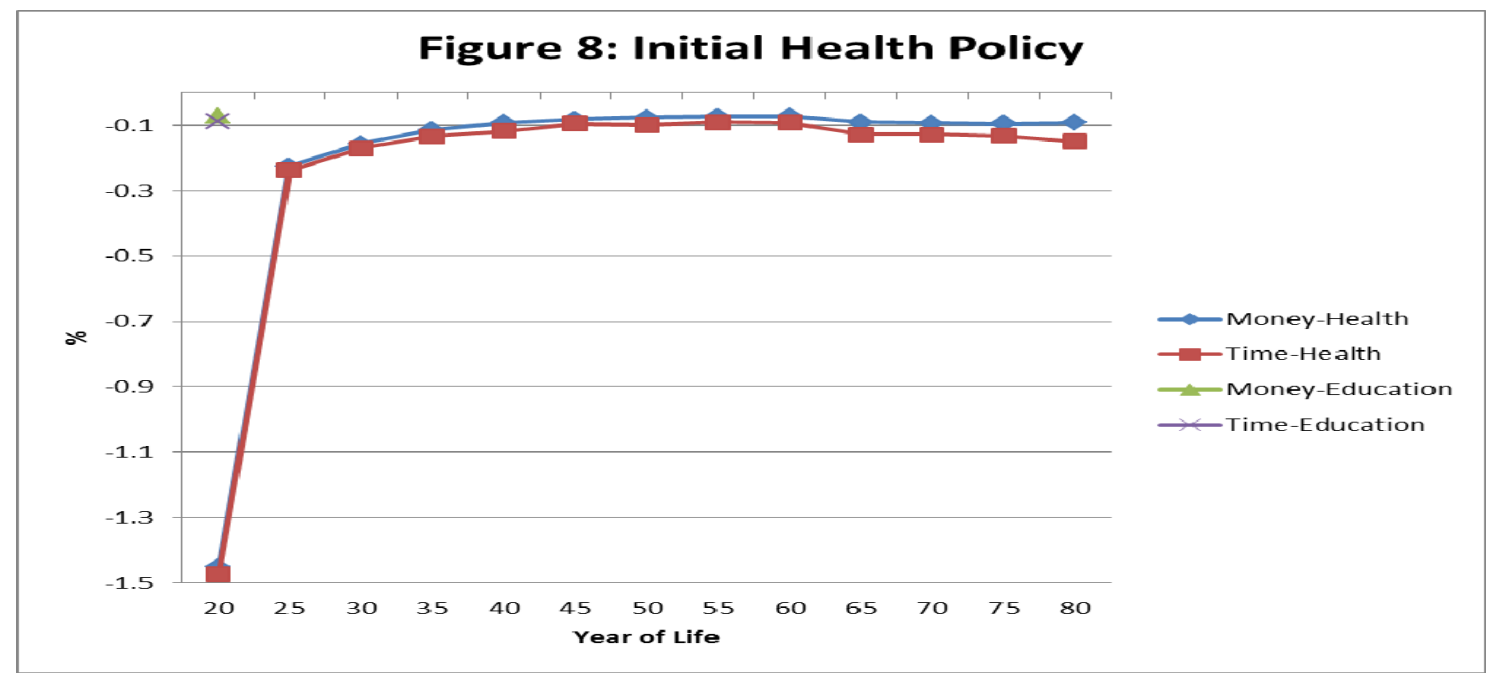

Figure 8 describes the results of the initial-health shock policy. Now the individual's health stock is exogenously altered but the relative prices of investment and consumption goods in the model remain unaltered. Because of this, it is interesting to compare the results of this experiment with the medical care subsidy, which combines an increase in health with a change in relative prices. Investments in both education and health fall under this scenario. Nevertheless, both the education and health stocks rise over the individual's lifetime. The reason the health stock rises is straightforward. If direct investments in education fall, then the fact that the education stock rises must be due to the indirect effect that the higher health stock has on education. Consumption rises as well. Thus, the individual uses the natural advantage accorded to it by the larger endowment of health to draw down investments and consume more. While we found ambiguous predictions on the sign of the changes in the investments levels for both health and education in the analytical model, the simulation results suggest that the negative substitution effects dominate at our calibration.

In contrast to this policy scenario, we saw that investments in education rise under the medical care subsidy. This is because the overall cost of living falls under the subsidy and does not here. 
This shows that health and education are not complements in this model in the sense that a higher health stock does not lead to high levels of investment in education. At the same time, it does lead to a higher level of education stock, because higher health increases the productivity of existing investments in education.

\subsection{Utility and life extension}

Figures 9 and 10 report the impacts of the policy scenarios on lifetime utility levels and life length respectively. Note that the initial health increase is not included in these figures as this policy is not comparable in magnitude to the other policy measures. Once again, quantities are reported as percentage changes from benchmark levels in the calibrated model. Naturally, all policies - which imply transfers to the individual - result in welfare gains. However, the gains vary substantially by policy. The effects on utility are largely a result of higher consumption, and a wealth transfer and an income tax reduction have significantly more positive effects on consumption than the subsidies on education and medical care. By definition, the initial wealth transfer leads to the largest increase in welfare. The income tax reduction yields slightly lowerthough nearly identical - benefits to the individual. In contrast, both the medical care subsidy and the education subsidy are dramatically less effective in welfare terms. The relative ranking of the policies is consistent with intuition. As discussed, the wealth transfer allows full flexibility to the individual in how to use these additional resources. All of the other policies considered imply some restriction on use or, equivalently, distort the relative prices faced by the individual, which leads to a higher cost of producing private well-being. The model suggests that the constraints these policies place on material consumption are quantitatively significant. Moreover, while the income tax reduction distorts only the choice between leisure and consumption, both the medical care and education subsidies additionally distort the choice between these goods and other forms of consumption. It follows that these policies would be expected to perform less well than the income tax reduction.

It is worth re-emphasizing at this point that we ignore any external, social benefits associated with investment in health or education. In practice, many of these benefits are thought to be quite large. Thus, subsidies to these activities may be justified on those grounds. Nevertheless, it is 
instructive to see the magnitude of the differences between the different policies as a measure of their relative costs.
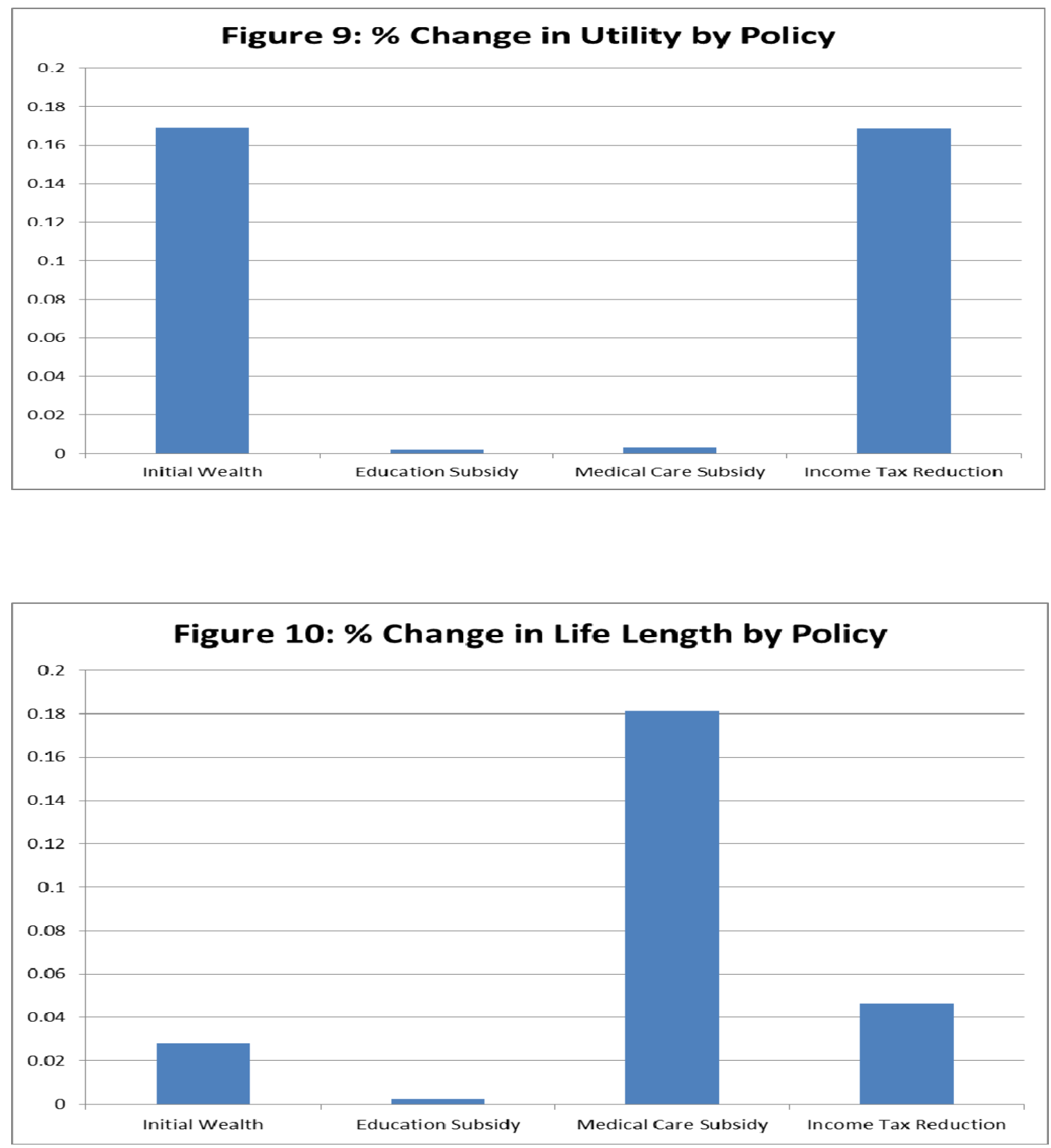

Life is extended under all policies. Note that the effect is dependent on the health path. As health is affected least under the education subsidy (see discussion on Figure 6) the expected lifetime increases very little as well. Not surprisingly, the largest effect is from subsidizing health directly, i.e., by introducing a medical care subsidy. As for lifetime utility, the effect of an increase in 
initial wealth is not very different from that of an income tax reduction. Both of these policies yield noticeably less life extension than the medical care subsidy, however. Thus, our simulation results show that the policies that effectively increase welfare may differ from policies that have significant life extension effects.

Under the initial wealth transfer, a one percent increase in lifetime wealth leads to approximately a $0.03 \%$ increase in the expected length of life. At a benchmark life length of 78 years, this increase amounts to a life that is longer by approximately 9 days. Extrapolated linearly, this would mean that a $50 \%$ increase in wealth would increase expected life length by approximately one and a quarter years. ${ }^{23}$ Taken another way, a one percent of present-value lifetime wealth for the calibrated income level in our model translates approximately into an annual payment of 200 present-value dollars in every year of life. Extrapolated linearly, an annual present-value wealth transfer of approximate $\$ 7200$ would be required to extend life by a year in our model. ${ }^{24}$

The other health outcome of interest in our model is sick days away from work. In our model, we assume that sick days are a function of the health stock only. Because life length also depends only on the health stock, the relative magnitudes of the effects on sick days follow the lifeexpectancy results described in Figure 10.

\subsection{Exploring the importance of causal linkages between education and health}

To explore the degree to which the interactions between health and education investments shape the results of our policy experiments, we conducted sensitivity analysis with respect the key parameters in the model that govern these interactions. Recall that the parameter $\alpha$ controls how the level of the education stock influences the productivity of investments in health. In our calibration of the benchmark model, this parameter takes on a value of approximately 0.008 . Similarly, the parameter $\mu$ controls how the level of the health stock influences the productivity

\footnotetext{
${ }^{23}$ By comparison, Statistics Canada reports that moving from the third after-tax income quintile (approximately $\$ 40,000$ in 2009 ) to the top income quintile (approximately $\$ 80,000$ in 2009) corresponds to an increase in life expectancy from 83.3 years to 84 years amongst females and from 78.7 years to 80.3 years amongst males. See http://www.statcan.gc.ca/pub/75-202-x/2009000/analysis-analyses-eng.htm for the report of income quintiles and http://www.statcan.gc.ca/pub/82-624-x/2011001/article/chart/11427-06-chart5-eng.htm for the report on life expectancy by income quintile.

${ }^{24}$ To compare this to data for the U.S., Tengs et al. (1995) found that prices of life-saving interventions varied a lot when comparing more than 500 interventions, but the median was about \$42,000 (1993-dollars) per life-year saved.
} 
of investments in education in the model. In the benchmark calibration, it takes on a value of approximately 0.02 . We conduct simulations in which we set one or both of these parameters equal to zero and then run the same set of policy experiments as described in section 6.1. When, for example, $\alpha$ is set equal to zero, the marginal effect of an increase in the education stock on the productivity of investments in health in the model is also zero. Thus, the incentive for the individual to invest in education to get the co-benefits in health that are present in our core model no longer exists. Similarly, when $\mu$ is set to zero, there no longer exists an incentive to invest in health to get co-benefits in education.

We find that the effect of changing these assumptions on behavior is small. This is consistent of the magnitude calibrated parameter values discussion in section 5.1. Removing the causal link from education to health has an almost imperceptible effect on the optimal pattern of investments the individual chooses. Removing the causal link from health the education has a small but perceptible effect. Intuitively, the individual invests somewhat less in their health when these investments no longer have a beneficial effect on their education stock. The change in the welfare and longevity gains due to the policy interventions we consider are also minimal in these sensitivity runs.

This suggests that neither of the interaction terms - from education to health or from health to education - is a likely candidate to explain much of the correlation between levels of education and health observed in the population. It also leaves other underlying factors that impact both outcomes as the remaining explanation for the pattern provided one accepts the calibration of our model. ${ }^{25}$ As we discussed at the outset, there is empirical evidence in the existing literature to support this view; there is evidence that cognitive ability (Auld and Sidhu, 2005; Cutler and Lleras-Muney, 2010), non-cognitive skills (Chiteji, 2010; van der Pol, 2011) and early childhood development factors (Conti and Heckman, 2010) may all play important roles in shaping the social gradient.

\footnotetext{
${ }^{25}$ Galama and van Kippersluis (2015) find self-reinforcement effects that may lead to the results even if the direct causal effect is not big. One example in their model is that life expectancy and skill capital productivity reinforce each other in generating skill.
} 
Our result that neither of the interaction terms appears to significantly affect the gains from investments in health and education is at odds with evidence that higher levels of education causes large gains in health (as in Cutler and Lleras-Muney, 2007). One possible explanation for this disparity is the absence of some behavioral effects in our model. That is, our model is deterministic and the agent exhibits perfect foresight in making consumption, saving and investment decisions. If households fail to fully optimize - either because of bounded rationality, imperfect information or because of uncertainty and risk aversion - then our model may overestimate the degree to which individuals can appropriate the gains from education-health interactions in the absence of government intervention. In that case, exogenous shocks that cause individual to obtain higher levels of education (such as the ones that lead to the identification strategies in the empirical literature) may lead to much larger gains than would be predicted by our model. Moreover, our calibration strategy relies on matching empirical observations on health and education investments to the predicted behavior of our model agent. Observing low levels of investments in these goods leads the model to attribute small utility gains from further investment in these activities (as opposed to attributing importance to any of the behavior effects discussed), leading to small parameter estimates and the modest effects that we find in our sensitivity analysis. We must also calibrate our model using incomplete measures of investment that likely misses significant amounts informal investment. Building these types of complications into a model like ours seems like a natural direction for future research.

\section{Conclusions}

In this study, we have produced analytical and numerical models of lifecycle investments in health and education. Both health and education have the potential to affect individual well-being through a number of distinct channels as well as to produce feedback effects between the two outcomes that past research on the nexus of health and education suggests are likely to be important.

Because of the close connections and feedbacks between health and education outcomes and the important policy implications of understanding the causal mechanism at work, researchers have devoted considerable effort to disentangling these effects. We contribute to this literature by 
proposing a new structural model of lifecycle health and education choices and analyzing which interpretation of the data a calibrated version of the model best supports.

Our analytical model identifies the key substitution and income effects that drive the changes in equilibrium investments expected in response to exogenous changes in wealth, health and related prices in the model. The perhaps unsurprisingly conclusion given the number of different ways health and education interact with well-being in the model, is that many of the net effects of the policy interventions we consider are ambiguous - with offsetting substitution and income effects.

We then calibrate an expanded, numerical model using US data on wages, consumption, life expectancy and expenditure levels on education and health. The numerical model allows us to quantify the effects of the policy responses and to determine which channels are likely to be most important in driving behavior.

In the policy scenarios we examine, we find that health and education investments are sometimes substitutes and at other times complements. A lump-sum wealth transfer and an income tax reduction are the most welfare-enhancing policies we consider. In a forward-looking model with perfect information, the lump-sum wealth transfer is destined to top the welfare rankings of different policy interventions. But the large gap in welfare gains between the policies that target wealth accumulation (wealth transfer and income tax reduction) and those that target health or education outcomes suggest these different approaches to public policy are not close substitutes. If we instead care for life extension, policies that are directed against health, such as medical care subsidy, are the most efficient. It must be emphasized, however, that our findings suggest only a private ranking of the policies. That is, they ignore any external benefits from subsidizing education or health.

Our research design also ignores any possible failures of the individual to optimize in the face of uncertainty, limits to information, rationality or other restrictions on behavior. The finding that health and education investments and their interactions, play a relatively small role relative to material consumption in promoting well-being could well be connected to these assumptions because our calibration strategy for the numerical model is predicated on rationalizing relatively 
low, observed levels of investments in these goods in a neoclassical framework. A natural direction for future research would be to explore models that relax these assumptions. 


\section{Appendix 1: Solving the two-period model}

The Lagrangian (L) is as follows:

$$
\begin{aligned}
\mathrm{L}= & \mathrm{u}\left(\mathrm{C}_{1}, \mathrm{e}_{0}, \mathrm{~h}_{0}\right) \\
& +1 /(1+\rho) \cdot \mathrm{S}\left(\mathrm{h}_{0}(1-\delta)+\mathrm{I}\left(\mathrm{IH}, \mathrm{TH}, \mathrm{e}_{0}+\mathrm{J}(\mathrm{TE}, \mathrm{IE})\right)\right) \cdot \mathrm{u}\left(\mathrm{C}_{2}, \mathrm{e}_{0}+\mathrm{J}(\mathrm{TE}, \mathrm{IE}), \mathrm{h}_{0}(1-\delta)+\mathrm{I}\left(\mathrm{IH}, \mathrm{TH}, \mathrm{e}_{0}+\mathrm{J}(\mathrm{TE}, \mathrm{IE})\right)\right) \\
& +\lambda\left\{\begin{array}{l}
\mathrm{n}_{0}+(\omega-\mathrm{TE}-\mathrm{TH}) \cdot\left(\mathrm{w}_{0}+\tau\right)-\mathrm{C}_{1}-\mathrm{P} \cdot \mathrm{IH}-\mathrm{Q} \cdot \mathrm{IE} \\
+1 /(1+\mathrm{r}) \cdot \mathrm{S}\left(\mathrm{h}_{0}(1-\delta)+\mathrm{I}\left(\mathrm{IH}, \mathrm{TH}, \mathrm{e}_{0}+\mathrm{J}(\mathrm{TE}, \mathrm{IE})\right)\right) \cdot\left[\omega \cdot\left(\mathrm{B}\left(\mathrm{e}_{0}+\mathrm{J}(\mathrm{TE}, \mathrm{IE})\right)+\tau\right)-\mathrm{C}_{2}\right]
\end{array}\right\} .
\end{aligned}
$$

Maximizing $L$ with respect to $T E, I E, I H, T H, C_{1}$ and $C_{2}$ gives the following 1 . order conditions, where $A=\omega \cdot\left(B\left(E_{2}\right)+\tau\right)-C_{2}$, i.e., wealth addition in period 2 :

$$
\begin{aligned}
& \text { (1) } \frac{\partial \mathrm{L}}{\partial \mathrm{TE}}=1 /(1+\rho)\left[\mathrm{S} \cdot\left(\mathrm{u}_{\mathrm{E}_{2}} \cdot \mathrm{J}_{\mathrm{TE}}+\mathrm{u}_{\mathrm{H}_{2}} \cdot \mathrm{I}_{\mathrm{E}_{2}} \cdot \mathrm{J}_{\mathrm{TE}}\right)+\mathrm{S}_{\mathrm{H}_{2}} \cdot \mathrm{I}_{\mathrm{E}_{2}} \cdot \mathrm{J}_{\mathrm{TE}} \cdot \mathrm{u}\left(\mathrm{C}_{2}, \mathrm{E}_{2}, \mathrm{H}_{2}\right)\right]-\lambda\left(\mathrm{w}_{0}+\tau\right) \\
& +1 /(1+\mathrm{r})\left[\cdot \lambda \mathrm{S}_{\mathrm{H}_{2}} \mathrm{I}_{\mathrm{E}_{2}} \mathrm{~J}_{\mathrm{TE}} \cdot \mathrm{A}+\lambda \mathrm{S}\left(\mathrm{H}_{2}\right) \cdot \omega \mathrm{B}_{\mathrm{E}_{2}} \mathrm{~J}_{\mathrm{TE}}\right]=0 \\
& \text { (2) } \frac{\partial \mathrm{L}}{\partial \mathrm{IE}}=1 /(1+\rho)\left[\mathrm{S} \cdot\left(\mathrm{u}_{\mathrm{E}_{2}} \cdot \mathrm{J}_{\mathrm{IE}}+\mathrm{u}_{\mathrm{H}_{2}} \cdot \mathrm{I}_{\mathrm{E}_{2}} \cdot \mathrm{J}_{\mathrm{IE}}\right)+\mathrm{S}_{\mathrm{H}_{2}} \cdot \mathrm{I}_{\mathrm{E}_{2}} \cdot \mathrm{J}_{\mathrm{IE}} \cdot \mathrm{u}\left(\mathrm{C}_{2}, \mathrm{E}_{2}, \mathrm{H}_{2}\right)\right]-\lambda \mathrm{Q} \\
& +1 /(1+r)\left[\lambda S_{\mathrm{H}_{2}} \mathrm{I}_{\mathrm{E}_{2}} \mathrm{~J}_{\mathrm{IE}} \cdot \mathrm{A}+\lambda \mathrm{S} \cdot \omega \cdot \mathrm{B}_{\mathrm{E}_{2}} \mathrm{~J}_{\mathrm{IE}}\right]=0 \\
& \text { (3) } \frac{\partial \mathrm{L}}{\partial \mathrm{TH}}=1 /(1+\rho)\left[\mathrm{S} \cdot \mathrm{u}_{\mathrm{H}_{2}} \cdot \mathrm{I}_{\mathrm{TH}}+\mathrm{S}_{\mathrm{H}_{2}} \cdot \mathrm{I}_{\mathrm{TH}} \cdot \mathrm{u}\left(\mathrm{C}_{2}, \mathrm{E}_{2}, \mathrm{H}_{2}\right)\right]-\lambda\left(\mathrm{w}_{0}+\tau\right)+1 /(1+\mathrm{r}) \cdot \lambda \mathrm{S}_{\mathrm{H}_{2}} \cdot \mathrm{I}_{\mathrm{TH}} \cdot \mathrm{A}=0 \\
& \text { (4) } \frac{\partial \mathrm{L}}{\partial \mathrm{IH}}=1 /(1+\rho)\left[\mathrm{S} \cdot \mathrm{u}_{\mathrm{H}_{2}} \cdot \mathrm{I}_{\mathrm{IH}}+\mathrm{S}_{\mathrm{H}_{2}} \cdot \mathrm{I}_{\mathrm{IH}} \cdot \mathrm{u}\left(\mathrm{C}_{2}, \mathrm{E}_{2}, \mathrm{H}_{2}\right)\right]-\lambda \mathrm{P}-1 /(1+\mathrm{r}) \lambda \cdot \mathrm{S}_{\mathrm{H}_{2}} \cdot \mathrm{I}_{\mathrm{IH}} \cdot \mathrm{A}=0 \\
& \text { (5) } \frac{\partial \mathrm{L}}{\partial \mathrm{C}_{1}}=\mathrm{u}_{\mathrm{C}_{1}}-\lambda=0 \\
& \text { (6) } \frac{\partial \mathrm{L}}{\partial \mathrm{C}_{2}}=1 /(1+\rho) \cdot \mathrm{S} \cdot \mathrm{u}_{\mathrm{C}_{2}}-1 /(1+\mathrm{r}) \cdot \lambda \cdot \mathrm{S}=0 \\
& \text { (7) } \frac{\partial L}{\partial \lambda}=n_{0}+(\omega-T E-T H) \cdot\left(w_{0}+\tau\right)-C_{1}-P \cdot I H-Q \cdot I E+1 /(1+r) \cdot S\left(H_{2}\right) \cdot A=0
\end{aligned}
$$

This gives 7 equations to determine $T E, T H, I E, I H, C_{1}, C_{2}$ and $\lambda$.

We find from (5) and (6): 
(8) $\lambda=u_{\mathrm{C}_{1}}=(1+\mathrm{r}) /(1+\rho) \cdot \mathrm{u}_{\mathrm{C}_{2}}>0$

Substituting for $\lambda$ gives us a system of 6 equations that can be written as equations (6)-(11) in Section 3. 


\title{
Appendix 2: Symbol definitions in the numerical model
}

\author{
Variables \\ $Z_{t}$ - full consumption \\ $C_{t}$ - market consumption \\ $L_{t}$ - leisure \\ $S_{t}$ - survivorship probability \\ $H_{t}$ - quality-of-life health stock \\ $W_{t}$ - wage rate \\ $E_{t}$ - education stock \\ $I H_{t}$ - investment in quality of life health \\ $I E_{t}$ - investment in education \\ $T H_{t}$ - investment in time on health \\ $T E_{t}$ - investment in time on education
}

\section{Parameters}

$\rho$ - discount rate

$\rho_{h z}-1 /\left(1-\rho_{h z}\right)-$ elasticity of substitution between health, education and full

consumption in utility

$\zeta$ - calibrated to imply a specific value for the intertemporal elasticity of substitution

$z_{0}$ - subsistence level of full consumption

$\kappa$ - calibrated to imply a specific value for the elasticity of substitution between consumption and leisure

$s l$ - value share of leisure in full consumption at age 50

$c_{0}$ - benchmark consumption at age 50

$l_{0}$ - benchmark leisure demand at age 50

$n_{0}$ - initial non-wage wealth 
$\omega$ - time endowment

$b_{t}$ - other non-wage assets

$p h_{0 t}$ - price of effective financial health investments

$p e_{0 t}$ - price of effective financial education investments

$p t h_{0 t}$ - price of effective time health investments

pte $_{0 t}$ - price of effective time education investments

$h_{0 t}$ - benchmark trajectory of $H_{t}$

$e_{0 t}$ - benchmark trajectory of $E_{t}$

$r$ - market interest rate

$\delta_{h}$ - depreciation rate of new investments in $H_{t}$

$\delta_{e}$ - depreciation rate of new investments in $E_{t}$

$v$ - parameter for productivity of time investments in health

$\alpha$ - parameter for productivity of education stock in health

$\beta$ - elasticity of health in sick days

$\gamma$ - elasticity parameter for productivity of money investments in health

$\mu$ - parameter for productivity of health stock in education

$\xi$ - parameter for productivity of time imvestments in education

$\eta$ - parameter for productivity of money investments in education

$\tau_{e}$ - share parameter of direct effects of education on utility

$\tau_{h}$ - share parameter of direct effects of health on utility

$\varepsilon$ - elasticity of time trend in productivity of health investments

$\psi$ - elasticity of time trend in productivity of education investments

$\phi$ - slope term in survivorship function

$\theta$ - exponent term in survivorship function. 


\section{Appendix 3: Description of the Numerical Model Calibration Procedure}

\section{1st Stage Calibration}

Formally, the model calibration proceeds in the following way. The first stage of the calibration follows the procedure described in Murphy and Topel (2006). Parameters $s l, c_{0}, l_{0}$ are calibrated to match consumption in midlife for the average individual based on expenditures and earnings data from the U.S. Bureau of Labor Statistics (2012a). In midlife, benchmark consumption and wage income are assumed to both be equal to approximately $\$ 60,000$. We also assume that households split their time evenly between work and leisure at midlife in the benchmark. $\kappa$ is chosen to imply representative estimates from the literature on the elasticity of substitution between consumption and leisure. In our benchmark model, this elasticity (defined at $1-1 / \kappa$ ) is equal to 0.5 . Similarly, $\zeta$ is chosen to ensure that the individual's survivorship-weighted average of willingness to pay for marginal reductions in the probability of death (their VSL) is equal to \$6.3 million (a number commonly used in benefit-cost assessments of policies designed to reduce mortality rates) between the ages of 25 and 55 given the values of the other parameters chosen. ${ }^{26}$

$z_{0}$, interpreted as the subsistence level of full consumption, is calibrated at $10 \%$ of the benchmark full consumption levels. $r$, the exogenous interest rate, is set equal to an annual rate of $4 \%$. $\rho$, the household's rate of time preference, is set equal to an annual rate of $2 \%$.

At this stage of the calibration procedure the survival probabilities, $S_{t}$, the health stock, $H_{t}$, and the education stock, $E_{t}$, are taken to be exogenous. $S_{t}$ values are chosen to match U.S. mortality data for the average individual, producing a benchmark expected life length of approximately 78 years. The mortality data are taken from Center for Disease Control and Prevention (2013). The trajectory of $H_{t}$ is chosen to reproduce the lifecycle consumption pattern represented in the BLS data. The education stock is set equal to benchmark levels $\left(e_{0 t}\right)$ which is assumed to follow the benchmark trajectory of wages generated by the BLS earning data (U.S. Bureau of Labor Statistics, 2012a). Candidate values are chosen for $\tau_{h}$ and $\tau_{e}$, which describe the relative

\footnotetext{
${ }^{26}$ See Viscusi and Aldy (2003) for a review of VSL estimates.
} 
importance of health, education and full consumption in generating household utility, and $\rho_{h z}$, which governs the degree of substitutability between these arguments. These values are updated in the final stage of the calibration.

This procedure represents a complete calibration of the model down to exogenous survivorship, health and education stocks. Thus it produces a benchmark sufficient to solve the reduced model:

$$
\max _{C, L} \sum_{t=1}^{T} S_{t} /(1+\rho)^{t-1}\left[\tau_{e} E_{t}^{\rho_{h z}}+\tau_{h} H_{t}^{\rho_{h z}}+\left(1-\tau_{e}-\tau_{h}\right)\left(\left(Z_{t}^{\zeta}-Z_{0}^{\zeta}\right) / \zeta\right)^{\rho_{h z}}\right]^{1 / \rho_{h z}}
$$

subject to

$$
n_{0}+\sum_{t}\left(\left(\omega-L_{t}\right) W_{t}+b_{t}-C_{t}\right) S_{t} /(1+r)^{t-1}=0
$$

$$
H_{t}=\bar{H}_{t}
$$

$$
E_{t}=\bar{E}_{t}
$$

plus equations (13) and (14). $\bar{H}_{t}$ and $\bar{E}_{t}$ represent exogenous levels of the health and education stock trajectories. The remaining tasks are to link survivorship to the level of health (2nd stage) and link health and education to the levels of financial and time investments in these stocks (3rd stage).

\section{2nd Stage Calibration}

The second stage of the calibration links the survivorship probability, $S_{t}$, to health status, $H_{t}$, by way of the function described in equation (14). The idea is to choose parameters in (14) to reproduce the survival data. However, the fit between the model function and the data will not be exact. As a result, the benchmark consumption and earning paths described by the first stage calibration will no longer be optimal for a given trajectory of $\bar{H}_{t}$. Thus, we update the $\bar{H}_{t}$ values to once again match the BLS consumption and earnings profiles - as we did in the first stage calibration - now at the new survival rate estimates. Formally, the algorithm is: 
1. If this is the first iteration of the algorithm, let $\bar{H}_{t}$ represent the trajectory implied by the outcome of the first stage calibration. If this is a subsequent iteration, let it represent the outcome from step 4 of the algorithm.

2. Choose the parameters of the suvivorship function ( $\phi$ and $\theta$ ) to minimize the sum of squared differences between the survivorship rates implied by the mortality data and the prediction from (14).

$$
\min _{\phi, \theta} D=\sum_{t}\left(1-e^{-\phi \bar{H}_{t}^{\theta}}-\bar{S}_{t}\right)^{2}
$$

where $\bar{S}_{t}$ represents the observed survivorship rates from the mortality data and $\bar{H}_{t}$ is the exogenous trajectory of the health stock.

3. Choose $\bar{H}_{t}$ such that the solution to (13)-(14) and (9)-(10) reproduces the observed consumption and earnings trajectories from the BLS data.

4. If there is no change in $\bar{H}_{t}$ from the previous iteration of the algorithm, then we are done. If not, return to step 1 .

In our application, this algorithm converges within 5 iterations.

\section{3rd Stage Calibration}

The third stage of the calibration chooses parameter values to match the model's prediction on the trajectories of benchmark health and education expenditure levels to data. The parameters calibrated here are: $\phi, \theta, \beta, \gamma, \eta, \tau_{e}, \tau_{h}, \alpha, \nu, \mu, \xi, \varepsilon, \psi$ and $\rho_{h z}$. We match data on monetary expenditures on health (medical expenditures), monetary expenditures on education and time expenditures on health and education. The data on medical expenditures come from the National Health Expenditures Data (2004). The data on monetary expenditures on education come from National Center for Education Statistics (2008) and the U.S. Census (2008). The data on time 
expenditures on education and health ${ }^{27}$ come from the American Time Use Survey (U.S. Bureau of Labor Statistics (BLS), 2012b).

To do this, we use a gradient descent method that proceeds in the following way.

1. Solve the optimization problem described by equations (12)-(17) holding the levels of the investment goods in model $\left(I H_{t}, T H_{t}, I E_{t}, T E_{t}\right)$ fixed equal to unity (a convenient normalization).

2. Extract the shadow values associated with the investment variables in the model and install effective prices for the investment goods that rationalize the levels of the investments as optimal levels. Thus if $V=U\left(C_{t}^{*}, L_{t}{ }^{*}, \mathrm{IH}_{t}=1, \mathrm{TH}_{t}=1, \mathrm{IE}_{t}=1, \mathrm{TE}_{t}=1\right)$ represents the maximand evaluated at the solution to the problem from step 1, where the “*” superscript indicates an optimal value for a model variable, then the effective shadow prices can be written as:

3.

$$
\begin{gathered}
p h 0_{t}=\frac{1}{\lambda} \frac{\partial V}{\partial I H_{t}} \frac{(1+r)^{t}}{S_{t}} \\
p e 0_{t}=\frac{1}{\lambda} \frac{\partial V}{\partial I E_{t}} \frac{(1+r)^{t}}{S_{t}} \\
p t h 0_{t}=\frac{1}{\lambda} \frac{\partial V}{\partial T H_{t}} \frac{(1+r)^{t}}{S_{t}} \frac{1}{E_{t}} \\
p t e 0_{t}=\frac{1}{\lambda} \frac{\partial V}{\partial T E_{t}} \frac{(1+r)^{t}}{S_{t}} \frac{1}{E_{t}}
\end{gathered}
$$

where $\lambda$ is the marginal utility of wealth.

\footnotetext{
${ }^{27}$ We do not include time spent on sports in this dataset as they are biased to the early part of life, and the model predictions make a better match with data without including sports.
} 
4. Compute the value of a loss function that measures the quadratic distance between data on the model investment goods and model predictions based on the realization from step 2. The loss function is defined as

$$
L=\sum_{t}\left(p h 0_{t}-\overline{p h 0}_{t}\right)^{2}+\left(p e 0_{t}-\overline{p e 0}_{t}\right)^{2}+\left(p t h 0_{t t}-\overline{p t h 0}_{t}\right)^{2}+\left(p t e 0_{t}-\overline{p t e}_{t}\right)^{2}
$$

where the "barred" values represent the calibration data.

5. Perturb the value of one parameter in the set of those to be calibrated in this stage. For example, set $\beta^{\prime}=\beta+\delta$ where $\delta$ is a small number.

6. Re-calculate the optimal shadow prices and loss function (as before in steps 1-3 for the perturbed parameter value. Call the value of the loss function that results from perturbing the level of parameter $i, L_{i}$.

7. Repeat steps 1-5 for all parameters to be calibrated.

8. Approximate the elements of the gradient of the loss function with respect to each parameter $i, l_{i}$, as:

$$
l_{i}=\frac{L_{i}-L}{\delta}
$$

9. If the elements of the gradient, $l_{i}$, are approximately equal to zero, then we are done.

10. If the gradient elements are not close to zero, update the vector of parameters, $P=\left[\beta, \gamma, \ldots \rho_{h z}\right]$, to a new set of candidate values, $P^{\prime}$, based on the evaluation of the gradient:

$$
P^{\prime}=P-\varpi \Lambda
$$

where $\Lambda=\left[l_{\beta}, l_{\gamma}, \ldots l_{\rho_{h z}}\right]$ and $\varpi$ is a speed of adjustment parameter.

11. Return to step 1. 
In practice, we set $\varpi=5 \mathrm{e}-7$ and run the third procedure for approximately 5000 iterations. 


\section{References}

Adams, P., M. D. Hurd, D. McFadden, A. Merrill and T. Ribeiro (2003): Healthy, wealthy, and wise? Tests for direct causal paths between health and socioeconomic status, Journal of Econometrics, 112: 3-56.

Almond, D., K. Y. Chay and D. S. Lee (2005): The costs of low birth weight, Quarterly Journal of Economics, 120(3): 1031-83.

Amin, V., J. R. Behrman, and T. D. Spector (2013): Does More Schooling Improve Health Outcomes and Health Related Behaviors? Evidence from U.K. Twins, Economics of Education Review, 35: 134-148.

Apouey, B. and A. E. Clark (2009): Winning Big but Feeling no Better? The Effect of Lottery Prizes on Physical and Mental Health, Notario di Lavoro 96.2009, Fondazione Eni Enrico Mattei, Milan.

Arias, E. (2012): United States Life Tables, 2008, National Vital Statistics Reports, 61(3).

Auld, M. C. and N. Sidhu (2005): Schooling, cognitive ability and health, Health Economics, 14: 1019-1034.

Becker, G. S. (1993): Human Capital - A Theoretical and Empirical Analysis, with Special Reference to Education, Third edition, The University of Chicago Press, Chicago and London.

Becker, G. S. (2007): Health as human capital: synthesis and extensions, Oxford Economic Papers, 59: 379-410.

Becker, G. S. and C. B. Mulligan (1997): The endogenous determination of time preference, Quarterly Journal of Economics, 112(3): 729-758.

Ben-Porath, Y. (1967): The production of human capital and the life cycle of earnings. Journal of Political Economy, 75: 353-367.

Behrman, J. R., H. Koher, V. M. Jensen, D. Pedersen, I. Petersen, P. Bingley, and K. Christensen (2011): Does More Schooling Reduce Hospitalization and Delay Mortality? New Evidence Based on Danish Twins, Demography, 48(4): 1347-1375.

Behrman, J. R. and M. R. Rosenzweig (2004): Returns to birth weight, Review of Economics and Statistics, 86(2), 586-601.

Berkman, L. F. (1995): The Role of Social Relations in Health Promotion, Psychosomatic Medicine, 57(3): 245-54. 
Bijwaard, G. E. and H. Van Kippersluis (2016): Efficiency of Health Investment: Education or Intelligence?, Health Economics, 25(9): 1056-1072.

Black, S. E., P. J. Devereux and K. G. Salvanes (2007): From the cradle to the labor market? The effect of birth weight on adult outcomes, Quarterly Journal of Economics, 122(1): 409-439.

Brunello, G., M. Fort, N. Schneeweis and R. Winter-Ebmer (2012): The causal effect of education on health: What is the role of health behaviors?, ISER Discussion Paper No. 836, Osaka, Japan.

Buckles, K., A. Hagemann, O. Malamud, M. Morrill and A. Wozniak (2016): The Effect of College Education on Mortality, Journal of Health Economics, forthcoming.

Case, A., A. Fertig and C. Paxson (2005): The lasting impact of childhood health and circumstance, Journal of Health Economics, 24: 365-389.

Carbone, J., S. Kverndokk and O. J. Røgeberg (2005): Smoking, Health, Risk, and Perception, Journal of Health Economics, 24: 631-653.

Cesarini, D., E. Lindqvist, R. Östling and B. Wallace (2016): Wealth, Health, and Child Development: Evidence from Administrative Data on Swedish Lottery Players, Quarterly Journal of Economics, 131(2): 687-738.

Chapman, K. S. and G. Hariharan (1996): Do Poor People Have a Stronger Relationship between Income and Mortality Than the Rich? Implications of Panel Data for Health-Health Analysis, Journal of Risk and Uncertainty, January 1996; 12(1): 51-63.

Chiteji, N. (2010): Time Preference, Noncognitive Skills and Well Being across the Life Course: Do Noncognitive Skills Encourage Healthy Behavior?, American Economic Review: Papers \& Proceedings 100: 200-204.

Chou, S.-Y., J.-T. Liu, M. Grossman, and T. J. Joyce (2010): Parental Education and Child Health: Evidence from a Natural Experiment in Taiwan, American Economic Journal: Applied Economics, 2(1): 33-61.

Clark, D. and H. Royer (2010): The effect of education on adult health and mortality: Evidence from Britain, Working Paper 16013, National Bureau of Economic Research, Cambridge, MA.

Conti, G. and J. Heckman (2010): Understanding the early origins on the education-health gradient: A framework that can also be applied to analyze Gene-environment interactions, Perspectives on Psychological Science, 5: 585-605.

Contoyannis, P., A. Jones and N. Rice (2004): The Dynamics of Health in the British Household Panel Survey, Journal of Applied Econometrics. July-Aug. 2004: 19(4): 473-503. 
Currie, J. and E. Moretti (2003): Mother's Education and the Intergenerational Transmission of Human Capital: Evidence from College Openings, Quarterly Journal of Economics, 118(4): $1495-1532$.

Cutler, D. M. and A. Lleras-Muney (2007): Education and Health: Evaluating Theories and Evidence, in J. S. House, R. F. Schoeni, G. A. Kaplan and H. Pollack (eds.), The Health Effects of Social and Economic Policy, New York: Russell Sage Foundation.

Cutler, D. M. and A. Lleras-Muney (2010): Understanding Differences in health Behaviors by Education, Journal of Health Economics, 29(1): 1-28.

Cutler, D. M., A. Lleras-Muney and T. Vogl (2011): Socioeconomic status and health: Dimensions and mechanisms, in S. Glied and P. C. Smith (eds.), Oxford Handbook of Health Economics, Oxford University Press, Oxford.

de Walque, D. (2007): Does education affect smoking behaviors?: Evidence using the Vietnam draft as an instrument for college education, Journal of Health Economics, 26: 877-895.

Edwards, R. D. (2010): Health, income, and the timing of education among military retirees, Working Paper 15778, National Bureau of Economic Research, Cambridge, MA.

Fabrice, E. and A. M. Jones (2011): Schooling and smoking among the baby boomers - An evaluation of the impact of educational expansion in France, Journal of Health Economics, 30(4): 811-831.

Fletcher, J. M. and S. F. Lehrer (2009): The Effects of Adolescent Health on Educational Outcomes: Causal Evidence Using Genetic Lotteries between Siblings, Forum for Health Economics \& Policy, 12(2): Article 8, The Berkeley Electronic Press.

Fonesca, R. and Y. Zheng (2011): The effect of education on health: Cross-country evidence, working paper WR-864, RAND Labor and Population working paper series.

Frijters, P., J. P. Haisken-DeNew and M. A. Shields (2005): The causal effect of income on health: Evidence from German reunification, Journal of Health Economics, 24: 997-1017.

Fuchs, V. R. (1982): Time Preference and Health: An Exploratory Study, in V. R. Fuchs (ed.), Economic Aspects of Health, University of Chicago Press for the National Bureau of Economic Research, pp. 93-120.

Fujiwara; T. and I. Kawachi (2009): Is education causally related to better health? A twin fixedeffect study in the USA, International Journal of Epidemiology, 38: 1310-1322.

Galama, T. J. and H. van Kippersluis (2015): A Theory of Education and Health, Tinbergen Institute Discussion Paper 2015-031/V, Tinbergen Institute, the Netherlands.

Gjerde, J., S. Grepperud and S. Kverndokk (2005): On adaptation and the demand for health, Applied Economics, 37: 1283-1301. 
Goldman, D. P. and J. P. Smith (2002): Can Patient Self-Management Help Explain the SES Health Gradient?, Proceedings of the National Academy of Science (PNAS), 99: 10929-10934.

Grossman, M. (1972): On the concept of health capital and the demand for health. Journal of Political Economy, 80: 223-255.

Grossman, M. (2000): The Human Capital Model, in: A. J. Culyer and J. P. Newhouse (eds.) Handbook of Health Economics. Elsevier Science B.V., Amsterdam, pp. 347-408.

Grossman, M. (2003): Household Production and Health. Review of Economics of the Household, 1: 331-342.

Grossman, M. (2008): Education and Nonmarket outcomes, in E. A. Hanushek and F. Welch (eds.): Handbook of the Economics of Education, vol. 1. Elsevier Science B.V., Amsterdam.

Grossman, M. (2015): The Relationship between Health and Schooling: What's New?, Nordic Journal of Health Economics, 3(1): 7-17.

Grossman, M. and R. Kaestner (1997): Effects of education on health, in: J. R. Behrman and N. Stacey (eds.) The Social Benefits of Education. University of Michigan Press, Ann Arbor, MI, pp. 69-123.

Hai, R. and J. J. Heckman (2015): A Dynamic Model of Health, Education, and Wealth with Credit Constraints and Rational Addiction, November 11, Available at SSRN:

http://ssrn.com/abstract=2688384.

Halliday, T. J., H. He and H. Zhang (2009): Health Investments over the Life-Cycle, IZA Discussion paper No. 4482, The Institute for the Study of Labor (IZA), Bonn, Germany.

Heckman, J. J. (2007): The economics, technology, and neuroscience of human capability formation, Proceedings of the National Academy of Science (PNAS), 104(33): 13250-13255.

Huisman, M., A. Kunst, M. Bopp. J. Borgan, C. Borrell, G. Costa, P. Deboosere, S. Gadeyne. M. Glickman, C. Marinacci, C. Minder, E. Regidor, T. Valkonen and J. P. Mackenbach (2005):

Educational inequalities in cause-specific mortality in middle-aged and older men and women in eight Western European populations, Lancet, 365: 493-500.

Jürges, H, E. Kruk and S. Reinhold (2013): The effect of compulsory schooling on healthevidence from biomarkers, Journal of Population Economics, 26(2): 645-672.

Koka, K., A. Laporte and B. Ferguson (2014): Theoretical simulation in health economics: An application to Grossman's model of investment in health capital, Working Paper No: 2014-11, Canadian Centre for Health Economics, Toronto, Ontario.

Kristensen, P., T. Bjerkedal, and L. M. Irgens (2004): Birthweight and work participation in adulthood, Int. J. Epidemiol., 33: 849-856. 
Lahelma, E., P. Martikainen, M. Laaksonen and A. Aittomäki (2004): Pathways Between Socioeconomic Determinants of Health, Journal of Epidemiology and Community

Health 58, 327-32.

Leigh, J. P. (1990): Schooling and Seat-belt use, Southern Economics Journal, 57(1): 195-207.

Lindahl, M. (2005): Estimating the Effect of Income on Health and Mortality Using Lottery Prizes as an Exogenous Source of Variation in Income, Journal of Human Resources. Winter 2005; 40(1): 144-68

Lleras-Muney, A. (2005): The relationship between education and adult mortality in the United States, Review of Economic Studies, 72: 189-221.

Lleras-Muney, A. (2006): Erratum: The relationship between education and adult mortality in the United States, Review of Economic Studies, 73: 847.

Lundborg, P. (2013): The health returns to schooling - what can we learn from twins?, Journal of Population Economics, 26(2): 673-701.

Madsen, M., A-M. Andersen, N., Christensen, P. K. Andersen, and M. Osler, (2010). Does Educational Status Impact Adult Mortality in Denmark? A Twin Approach, American Journal of Epidemiology, 172(2): 225-234.

Madsen, J, (2012): Health, human capital formation and knowledge production: Two centuries of international evidence, Working Paper 18461, National Bureau of Economic Research, Cambridge, MA.

Mazumder, B. (2012): The effects of education on health and mortality, Nordic Economic Policy Review, 1: 261-301.

Marmot, M. (2004): The Status Syndrome: How Social Standing Affects our Health and Longevity, Times Books, New York.

Meghir, C., M. Palme and E. Simeonova (2012): Education, health and mortality: Evidence from a social experiment, Working Paper 17932, National Bureau of Economic Research, Cambridge, MA.

Michael, R. T. (1973): Education in Nonmarket Production, Journal of Political Economy, 81(2), Part 1: 306-327.

Mincer, J. (1974): Schooling, Experience, and Earnings. Columbia University Press for the National Bureau of Economic Research, New York.

Murphy, K. M. and R. H. Topel (2006): The Value of Health and Longevity, Journal of Political Economy, 114(5): 871-904. 
Muurinen, J. (1982): Demand for Health: A generalised Grossman model, Journal of Health Economics, 1: 5-28.

Rutherford, T. F. (2002): Lecture Notes on Constant Elasticity Functions, mimeo. http://www.gamsworld.org/mpsge/debreu/ces.pdf

Scholz, J. K. and A. Seshadri (2010): Health and Wealth in a Life Cycle Model, Working Paper 2010-224, University of Michigan Retirement Research Center.

Smith, J. P. (2007): The impact of socioeconomic status on health over the life course, Journal of Human Resources, 42(4): 739-764.

Strulik, H. (2013): Health and Education: Understanding the Gradient, Discussion Paper 172, Center for European, Governance and Economic Development Research - cege, Georg August Universität Göttingen.

Tengs, T. O., M. E. Adams, J. S. Pliskin, D. G. Safran, J. E. Siegel, M. C. Weinstein and J. D. Graham (1995): Five-Hundred Life-Saving Interventions and Their Cost-Effectiveness, Risk Analysis, 15(3): 369-390.

U.S. Bureau of Labor Statistics (BLS) (2012a): Consumer Expenditure Survey, http://www.bls.gov/cex/home.htm

U.S. Bureau of Labor Statistics (BLS) (2012b): American Time Use Survey, http://www.bls.gov/tus/current/education.htm.

U.S. Bureau of Labor Statistics (BLS) (2013): Civilian workers, by major occupational and industry group, http://www.bls.gov/news.release/ecec.t01.htm.

U.S. Center for Disease Control and Prevention (CDC) (2013): National Vital Statistics System, Mortality Data, http://www.cdc.gov/nchs/deaths.htm

U.S. Centers for Medicare and Medicaid Services (2004): National Health Expenditure Data, http://www.cms.hhs.gov/NationalHealthExpendData/04_NationalHealthAccountsAgePHC.asp.

U.S. Department of Commerce, Census Bureau (2008): Current Population Survey.

van der Pol, M. (2011): Health, education and time preferences, Health Economics, 20: 917-929.

van Kippersluis, H., O. O’Donnell and E. van Doorslaer (2011): Long-Run Returns to Education Does Schooling Lead to an Extended Old Age?, Journal of Human Resources, 46(4): 695-721.

Viscusi, W. K. and J. E. Aldy (2003): The Value of a Statistical Life: A Critical Review of Market Estimates throughout the World, Journal of Risk and Uncertainty, 27(1): 5-76. 